\title{
1 Fly ash-slag interaction during alkaline activation: Influence of activators on phase assemblage and microstructure formation
}

5 Department of Civil and Environmental Engineering, The Pennsylvania State University, 3127

* Corresponding author. Email: huy131@psu.edu Phone: +001 484-260-4003

9 Abstract: In this work, the influence of activator on the interaction mechanisms between slag

10 and low-calcium fly ash (FA-F) during alkaline activation was investigated. In particular, the

11 evolution of phase assemblage and microstructure of alkali-activated binary slag and FA-F paste

12 was monitored by means of X-ray diffraction with Rietveld analysis, scanning electron

13 microscopy, and energy-dispersive spectroscopy (SEM/EDS). The results show that the nature of

14 amorphous gels and type of crystalline phases formed are dependent on sample age, initial slag

15 to FA-F ratio, and activator type and dosage. The interaction between FA-F and slag during

16 alkaline activation or geopolymerization is primary demonstrated as: (1) modified nanostructure

17 (e.g. crystallology and lattice parameters) and chemical composition of precipitates, (2)

18 depressing or triggering the formation of some crystalline phases, and (3) spatial heterogeneity of

19 composition in microstructure. The activator is chemically incorporated into interactions between

20 slag and FA-F, and likely affects the dissolution and reaction kinetics. 
22 Keywords: Alkali-activated binder; Geopolymer; Calcium-alumina-silicate-hydrate;

23 Alkali-aluminosilicate-hydrate; Fly ash-slag blends.

\section{1. Introduction}

27 Due to environmental concerns related to cement and concrete production, repurposing of

28 ground-granulated blast furnace slag (GGBFS) and Class F fly ash (FA-F) into infrastructure

29 materials has been gaining wider attention [1, 2]. As GGBFS and FA-F are both industrial

30 by-products with remarkable cementitious or pozzolanic activities, alkali-activated binary FA-F

31 and slag materials have become one of most promising alternative binders to ordinary Portland

32 cement (OPC) [3, 4]. The combined use of FA-F and slag for preparing alkali-activated binders

33 has several advantages over either pure alkali-activated slag (AAS) or pure FA-F-based

34 geopolymer alone. For instance, addition of small dosages of slag into $\mathrm{NaOH}$-activated

35 FA-F-based geopolymer can potentially resolve its setting problems, since $\mathrm{NaOH}$-activated FA-F

36 typically takes much longer time to harden at room temperature than OPC [5]. On the other hand,

37 as AAS has considerable chemical and drying shrinkage [6-8], the incorporation of FA-F in AAS

38 binders can enhance its volumetric stability [9]. With respect to further implementation in

39 construction field, the physical and engineering properties of alkali-activated FA-F/slag binders

40 must be known. There is no doubt that the properties of these binders are inherently controlled by 
41 the main hydration products formed during the activation process [10].

43 Previous research has revealed that slag and FA-F, when separately activated, exhibit distinct

44 hydration products [11, 12]. Basically, the main hydration product in AAS binders is

45 calcium-alumina-silicate-hydrate (C-A-S-H), while for pure FA-F-based geopolymers, it is rich

46 in alkali-aluminosilicate-hydrate (N-A-S-H) [12]. It has been widely shown that C-A-S-H

47 formed in AAS has a lamellar structure with a strong similarity to the structure of tobermorite

48 [13-15]. The $\mathrm{Al}^{3+}$ in C-A-S-H is incorporated in the dreierketten silicate chains and substitutes

$49 \mathrm{Si}^{4+}$, which is charge balanced by alkali or $\mathrm{Ca}^{2+}$ cations [16]. In case of N-A-S-H, $\mathrm{Si}^{4+}$ and $\mathrm{Al}^{3+}$

50 are arranged in tetrahedral forms to create 3D structures, with alkaline cations (e.g. $\mathrm{Na}^{+}$)

51 compensating the charge balance associated with $\mathrm{Al}^{3+}$. In addition, the $\mathrm{Al} / \mathrm{Si}$ ratio in $\mathrm{N}-\mathrm{A}-\mathrm{S}-\mathrm{H}$

52 varies and typically ranges from 0.28 to 0.36 [17]. Similarities between N-A-S-H gel structure

53 and the structure of zeolites have been reported in numerous papers [17-19]. For alkali-activated

54 FA-F/slag binary materials, the main hydration product is in a $\mathrm{Na}_{2} \mathrm{O}-\mathrm{CaO}-\mathrm{Al}_{2} \mathrm{O}_{3}-\mathrm{SiO}_{2}-\mathrm{H}_{2} \mathrm{O}$

55 system, and the hydrated products are reported to contain both N-A-S-H, C-A-S-H, and

56 potentially N-C-A-S-H [20]. Recent study has shown that there may exist chemical interactions

57 between slag and FA-F during alkaline activation and geopolymerization process [21, 22]. In

58 addition, it was reported that the nature of hydrated products formed in binary systems are

59 influenced by the FA-F/slag ratio [20, 22, 23], temperature [24], alkaline activator (e.g. pH,

60 dissolved silica) [25]. 
62 Despite an extensive previous investigation, the interaction mechanism between slag and FA-F,

63 as well as the influence of activator on this interaction remains unclear. Recent investigators

64 attempted to explore the potential interaction mechanisms between slag and FA-F, including

65 reaction mechanisms [26], chemical composition [20], gel structure [22], and pore structure [27].

66 For example, Lee et al. found that although the geopolymeric gel can contain a considerable

67 amount of $\mathrm{Ca}$ (i.e. N-C-A-S-H), which has nearly the same chemical composition as C-A-S-H,

68 their silicate structures are different [22]. Ismail et al. reported that a hybrid N-C-A-S-H gel can

69 be identified as part of the Ca released by slag dissolution is incorporated into the N-A-S-H type

70 gel resulting from fly ash activation [20]. Provis et al. found that low calcium content (i.e. low

71 slag/FA-F ratio) can not induce the formation of specific Ca-rich gel phases, and suggests some

72 extent of incorporation of Ca into the N-A-S-H gels [27]. It can be seen that the exact mechanism

73 between slag and FA-F during alkaline activator and the influence of activator on this interaction

74 still remain unknown.

76 This study aims to illuminate the interaction mechanisms between slag and FA-F by monitoring

77 the phase assemblage and microstructural evolution of the alkali-activated FA-F/slag binary

78 materials. In addition, the influence of the dissolved silica $\left(\left[\mathrm{SiO}_{2}\right] \mathrm{aq}\right)$ and $\mathrm{pH}$ of the activator

79 solutions on the early-age interaction during activation or geopolymerization process is explored.

80 Particularly, X-ray diffraction with Rietveld semi-quantitative analysis, scanning electron 
81 microscopy, and energy-dispersive spectroscopy (SEM/EDS) were implemented to monitor the

82 evolution of hydrated phases, microstructure, and chemical composition of binary system as a

83 function of age, slag/FA-F ratio, and activator. Furthermore, a series of ternary phase diagrams

84 combined with statistical composition distribution were analyzed, to further understand the 85 interaction mechanisms.

\section{2. Experimental procedures}

\subsection{Materials}

90 Class F fly ash (ASTM C 618-08) and Grade 120 ground-granulated blast-furnace slag (ASTM

91 C989M-12a) were utilized in this study. The chemical compositions, specific gravity, and

92 particle size distributions of these two raw materials are listed in Table 1 and Figure 2,

93 respectively. To prepare activator solution, a combination of sodium silicate and $\mathrm{NaOH}$ solutions

94 was used. The sodium silicate $\left(\mathrm{Na}_{2} \mathrm{O} \cdot\left(\mathrm{SiO}_{2}\right)_{1.6} \cdot\left(\mathrm{H}_{2} \mathrm{O}\right)_{\mathrm{x}}\right)$ had a modulus of 1.6 (by molar), pH of

9513.7 , and specific gravity of 1.60 at $20^{\circ} \mathrm{C}$. The $\mathrm{NaOH}$ solution was prepared using pellets and

96 distilled water. The activators were dissolved in distilled water prior to the mixing in order to

97 have a homogenous distribution, further sealed in airtight containers to prevent carbonation and

98 evaporation, and then cooled to room temperature ahead of mixing time. 
Table 1 Oxide compositions and specific gravity of FA-F and raw slag (mass \%)

\begin{tabular}{|c|c|c|c|c|c|c|c|c|c|c|c|c|c|c|}
\hline & $\mathrm{CaO}$ & $\mathrm{SiO}_{2}$ & $\mathrm{Al}_{2} \mathrm{O}_{3}$ & $\mathrm{MgO}$ & $\mathrm{SO}_{3}{ }^{\mathrm{a}}$ & $\mathrm{S}^{2-}$ & $\mathrm{Fe}_{2} \mathrm{O}_{3}$ & $\mathrm{Na}_{2} \mathrm{O}$ & $\mathrm{K}_{2} \mathrm{O}$ & $\mathrm{P}_{2} \mathrm{O}_{5}$ & $\mathrm{MnO}$ & $\mathrm{TiO}_{2}$ & LOI & $\begin{array}{l}\text { Specific } \\
\text { gravity }\end{array}$ \\
\hline Slag & 43.83 & 30.04 & 12.74 & 4.79 & 3.11 & 0.85 & 1.16 & 0.24 & 0.40 & 0.08 & 0.22 & - & 2.56 & 2.89 \\
\hline FA-F & 2.53 & 48.67 & 25.13 & 0.86 & 1.46 & - & 16.08 & 1.04 & 1.97 & 0.26 & 0.04 & 1.03 & 1.58 & 2.50 \\
\hline
\end{tabular}

102 Note: a: The element compositions were measured by ICP-AES method, the relatively high $\mathrm{SO}_{3}$

103 content in slag is primarily due to the presence of gypsum

104

105

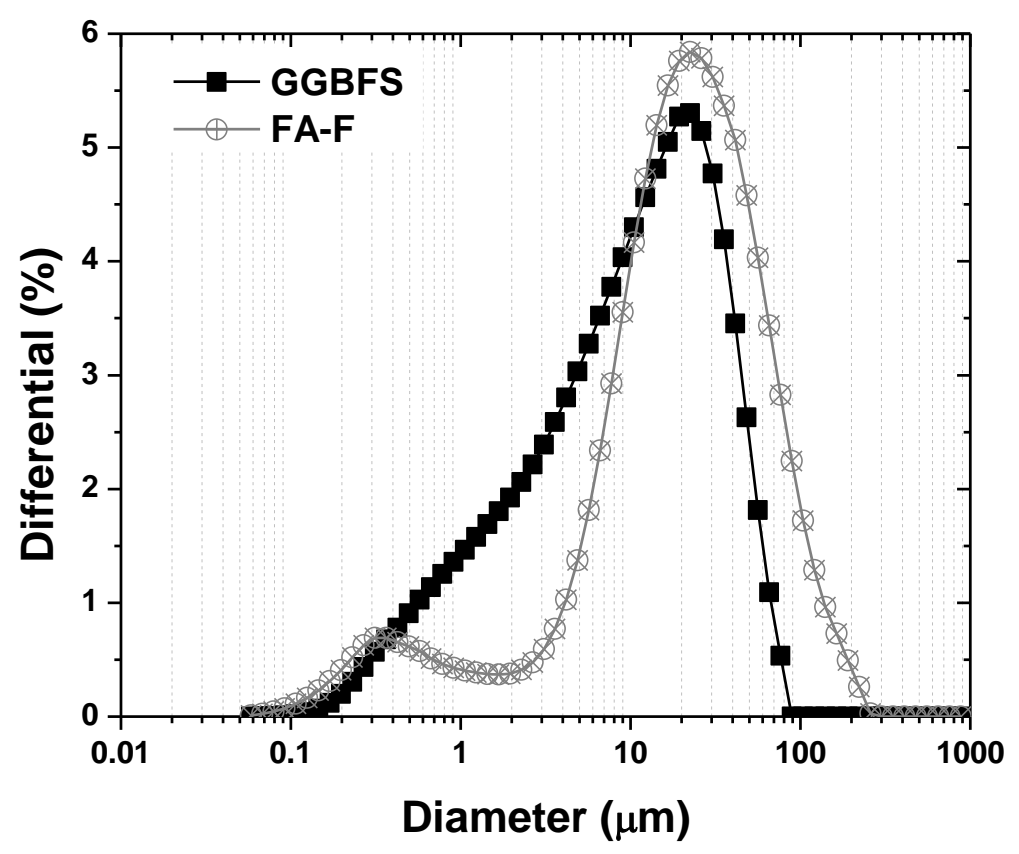

106 Figure 1 Particle size distribution of raw slag and FA-F obtained by laser diffraction 
110 In this study, FA-F/slag-based geopolymer pastes prepared by three different activators were

111 investigated. Volumetric mixture proportioning was implemented by keeping the initial liquid

112 (activating solution) to solid (FA-F and slag) volumetric ratio constant at 0.75 for all samples, as

113 shown in Table 2. The selection of this volumetric ratio ensured that all mixtures have the same

114 initial porosity although the workability would vary. Considering the different densities between

115 FA-F and slag, as well as among various activators, the mass ratio for each mixture varies.

116 Additionally, three different types of solutions, namely sodium silicate (NS), 6M NaOH (HN),

117 and $2 \mathrm{M} \mathrm{NaOH}(\mathrm{LN})$ were used as activators. The initial volumetric ratio between raw FA-F and

118 slag were set to be $100 / 0,80 / 20,50 / 50,20 / 80$, for each individual type of activator. The pure

119 AAS binder was neglected in this study, since a systematic study on the phase evolution and

120 microstructure characteristics for the same slag with a broad range of activator type/dosage have

121 been reported by the authors previously [8]. After mixing, each sample was cast in a sealed

122 plastic container to prevent evaporation and carbonation, and was further kept at constant

123 temperature of $23 \pm 0.5^{\circ} \mathrm{C}$, until reaching the desired age (i.e. 1 day, 7 days, and 28 days) for

124 further characterization as described below.

127 Table 2 Mixture proportions for alkali-activated binary FA-F/slag-based geopolymer pastes 


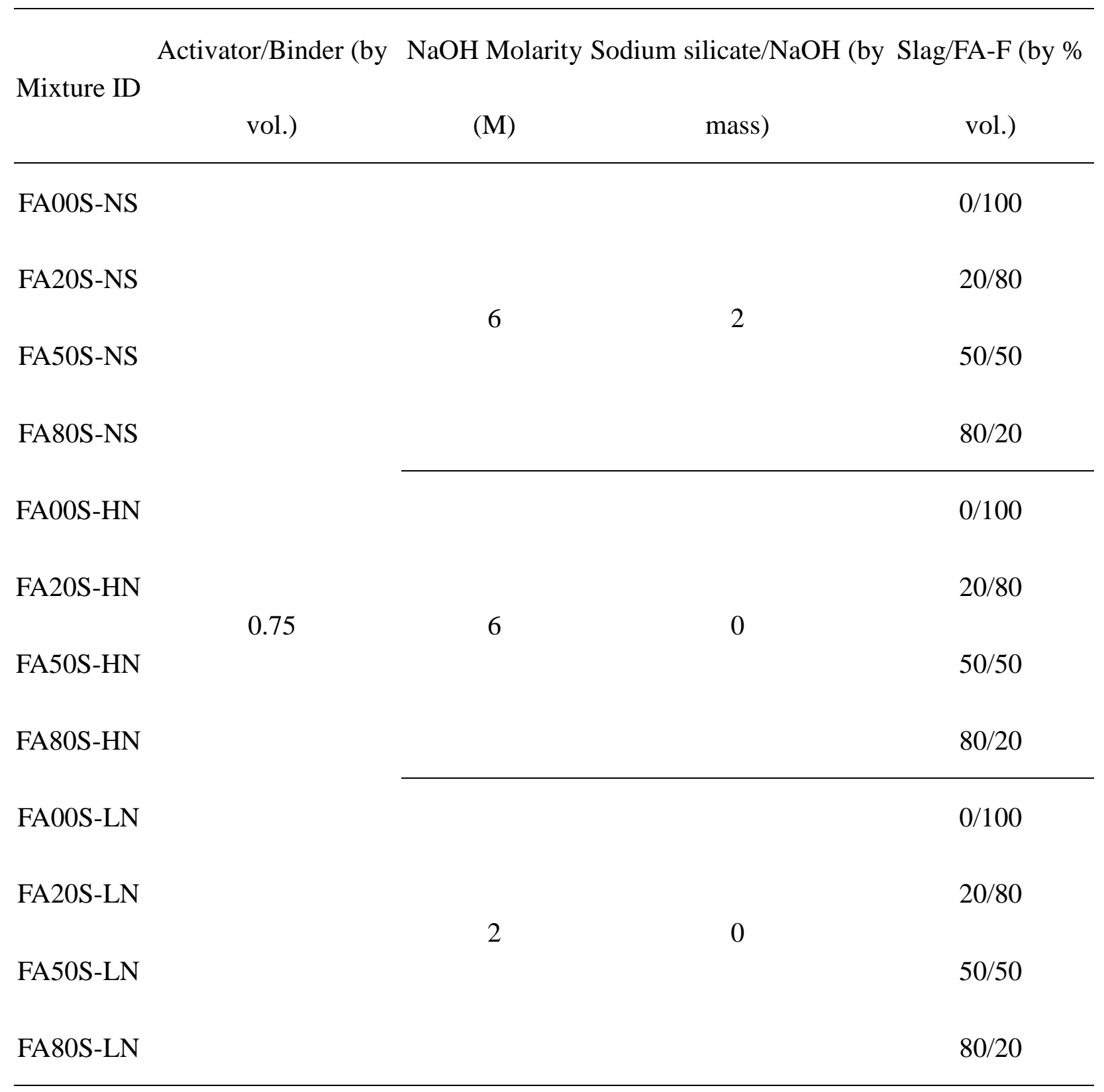

131 Prior to X-ray diffraction (XRD) test, paste samples were crushed and immersed into isopropyl

132 alcohol to stop further hydration at the desired age, and then vacuum-dried before milling to fine 
133 size. Furthermore, 3\%-4\% crystalline Nickle powder was admixed in each sample as an internal

134 standard for Rietveld analysis. The samples were further front-filled into a zero-background plate

135 and continuously scanned between $5^{\circ}$ and $70^{\circ} 2 \theta$ under the conditions as follows.

137 XRD data was collected using a PANalytical Empyrean diffractometer in a conventional

138 Bragg-Brentano $\theta-2 \theta$ configuration using $\mathrm{CuK} \alpha$ radiation $(\lambda=1.5418 \AA)$ with a diffractometer

139 radius of $240 \mathrm{~mm}$. CuK $\alpha$ X-ray was generated using $40 \mathrm{~mA}$ and $45 \mathrm{kV}$ operating conditions.

140 Incident beam Soller slits of $0.04^{\circ}$ were used, and the incident divergence and anti-scatter slits

141 were fixed at $0.25^{\circ}$ and $0.5^{\circ}$, respectively. Air scattering was reduced using a beam knife. The

142 beam width was $10 \mathrm{~mm}$ and no receiving slit was used, but an anti-scatter slit was fixed at $0.25^{\circ}$

143 and the Soller slits limiting the axial divergence to 0.04 radians were positioned in the diffracted

144 beam path. Instead of using monochromators, a beta-filter Nickle was used to eliminate the $\beta$

145 diffraction spectrums. A PIXcel3D 1x1 solid-state detector with a total of 255 active channels

146 and an active length of $3.3473^{\circ}$ was used for data acquisition.

148 Rietveld semi-quantitative analysis was implemented in this research to determine the quantities

149 of crystalline and amorphous components in alkali-activated FA-F/slag binary materials. The

150 principle of Rietveld method is to minimize the inconsistency between measured and calculated

151 powder diffraction patterns, by adjusting numerous parameters in particular structural models [28,

152 29]. The structural model in Rietveld method can account for various systematic errors in 
153 experimental data (e.g. preferred orientation(s), peak broadening, and peaks overlap) [28]. In

154 case of alkali-activated FA-F/slag binary materials, a challenge of quantifying such complex

155 material is due to the presence of amorphous phases in considerable amounts, including both

156 unhydrated raw materials and disorderly formed gels. In order to relatively accurately obtain the

157 amorphous content, a known amount of crystalline Nickle was added as mentioned before. The

158 Rietveld quantitative analysis was performed by Jade software (Material Data Inc.).

$160 \quad 2.4$ SEM/EDS

161 Prior to SEM/EDS, samples were first cut into small slices and immersed into isopropyl alcohol

162 at desired age to stop hydration. The samples were further subjected to vacuum-drying, epoxy

163 impregnation, followed by polishing down to $1 / 4 \mu \mathrm{m}$, and carbon-coating. The SEM/EDS were

164 performed on FEI Quanta 200 at an accelerating voltage of $20 \mathrm{kV}$, equipped with solid-state

165 backscattered detector and X-ray microanalysis system. The backscattered electron (BSE)

166 images were acquired, in which the contrast is primarily dependent on the average atomic

167 number of the area being examined.

169 For EDS microanalysis, about 50-100 spots were analyzed at different representative locations

170 on the hydrated products (i.e. excluding unreacted slag or/and FA-F particles) for each sample to

171 reduce random errors. Considering the semi-quantitative nature and limited probing length scale

172 of EDS, the X-ray microanalyses may relate to mixtures of phases (e.g. C-A-S-H, N-A-S-H, 
173 C-N-A-S-H) in varying proportions for alkali-activated binary system. In addition, EDS line

174 scanning was implemented to obtain the chemical evolution between slag and FA-F.

\section{3. Results and Discussion}

$178 \quad 3.1$ XRD mineralogical analysis

179 X-ray powder diffraction patterns for all the materials studied, including the original raw FA-F

180 and slag, are shown in Figures 2 to 5. FA-F is an essentially vitreous material (see halo recorded

181 for $2 \theta=20 \sim 35^{\circ}$ ), with various crystalline phases, mainly quartz (black solid line), mullite (black

182 dashed line), hematite (black short dotted line), magnetite (light grey solid line), and traces of

183 halite (light grey dashed line). However, blast-furnace slag contains primarily amorphous phases,

184 with trace of gypsum (blue solid line) and alite (blue dashed line).

186 Figure 2 shows the XRD patterns for pure FA-F activated by various types (i.e. NS, HN, and LN)

187 of activators. Besides the newly precipitated crystalline phases, alkali-activated pure FA-F has a

188 different background profile than unhydrated FA-F, indicating the alteration in amorphous

189 structures and formation of poorly crystalline sodium aluminosilicate hydrate (N-A-S-H) phases.

190 It can be seen that different activators can affect the types of N-A-S-H gels. For sodium

191 silicate-activated FA-F, no strong additional peak is observed, while for NaOH-activated FA-F

192 regardless of $\mathrm{pH}$, various new crystalline phases, including N-A-S-H, Zeolite X-type phases, and 
193 Chabazite can be detected at later age. In particular, two types of N-A-S-H were detected: one is

$194 \mathrm{Na}_{6}\left(\mathrm{AlSiO}_{4}\right)_{6} \cdot 4 \mathrm{H}_{2} \mathrm{O}$, preferably found in $\mathrm{HN}$-activated system, another one is

$195 \mathrm{Na}_{1.4} \mathrm{Al}_{2} \mathrm{Si}_{3.9} \mathrm{O}_{11.5} \cdot \mathrm{H}_{2} \mathrm{O}$ in $\mathrm{LN}$-activated system. These strong crystalline N-A-S-H peaks appear

196 and magnify (i.e. increasing peak intensity) as age increases, indicating an ongoing activation

197 and structural evolution (e.g. reorganization and crystallization) is taking place.

198

199 The different types of crystalline N-A-S-H phases between $\mathrm{HN}$ - and LN-activated systems,

200 imply that the initially formed amorphous and gelled structure at the initial stage of activation is

201 also different, since the nature of predominant geopolymeric gel closely relates to the ending

202 crystalline phases (as a result of amorphous-crystalline transformation [30]). Basically, the

203 amorphous or semi-crystalline $\mathrm{N}-\mathrm{A}-\mathrm{S}-\mathrm{H}$ gel in geopolymer is characterized in literature is a

204 zeolite-precursor [17], and tends to crystallize [30]. This research supports it and further

205 illustrates that the structure of geopolymeric gels is significantly influenced by the activator type

206 and dosage. In addition, there is an evidence that high $\mathrm{pH}$ increases the crystallization of

207 geopolymeric gel, while dissolved silica ([SiO2]aq) promotes a more structural disorder in

208 hydrated phases. This is reasonable, since sodium silicate itself is an amorphous material and can

209 be involved during the activation processes. This finding is consistent with the research focused

210 on the influence of different activators on the hydrated phases in pure AAS [8, 31].

212 Figure 3 shows the XRD patterns for binary $80 \%$ FA-F with $20 \%$ slag activated by various 
213 solutions. Similarly to alkali-activated pure FA-F, various N-A-S-H phases can be observed

214 when activated by $\mathrm{NaOH}$ solutions, which are absent in the NS-activated system. In contrast to

215 the pure alkali-activated FA-F, small incorporation of slag triggers the formation of a broad and

216 diffusive hump at around $29^{\circ} \sim 31^{\circ}$. This new hump corresponds to $\mathrm{C}-\mathrm{S}-\mathrm{H}$, which is primarily

217 from the hydration of slag. As further characterized by EDS-ternary diagram analysis (see

218 Section 3.4), the small incorporation of slag renders some regions in $\mathrm{SiO}_{2}-\mathrm{CaO}-\mathrm{Al}_{2} \mathrm{O}_{3}$ phase

219 diagram where the detected chemical composition is similar to C-A-S-H. It likely indicates that a

220 small amount of C-A-S-H is occasionally and unevenly formed in this system. In addition, the

221 number and intensity of crystalline N-A-S-H and other zeolite-type phases decrease because of

222 slag incorporation. It is probably due to the incorporation of $\mathrm{Ca}$ into the N-A-S-H phase by ion

223 exchange between $\mathrm{Ca}^{2+}$ with $\mathrm{Na}^{+}$, which suppresses the crystallization. It may indicate that the

224 hydration process of slag and FA-F are not linearly independent but an interaction exists between

225 slag and FA-F.

227 Figure 4 shows the XRD patterns for binary 50\% FA-F with $50 \%$ slag activated by various

228 solutions. Contrary to Figure 2 and Figure 3, no strong crystalline N-A-S-H and zeolite-type

229 peaks can be observed after 28 days curing in alkali-activated FA-F with $50 \%$ slag replacement.

230 Instead, a series of strong broad and diffusive humps appearing around $30^{\circ}$ can be detected,

231 which is believed to be due to the extensive generation of C-A-S-H. Similar to pure AAS [8, 32],

232 primarily two types of $\mathrm{C}(-\mathrm{A})-\mathrm{S}-\mathrm{H}$ gels (i.e. $\mathrm{C}-\mathrm{S}-\mathrm{H}(\mathrm{I})$ and $\mathrm{C}-\mathrm{S}-\mathrm{H}$ ) can be detected by XRD. In 
233 comparison to C-S-H, C-S-H (I) has a more ordered structure in XRD pattern and presents a

234 broad, basal reflection corresponding to the mean interlayer thickness. It should be noted that this

235 C-S-H (I) is actually C-A-S-H, as evidenced by the chemical composition (EDS) and structural

236 modifications (XRD) due to Al substitution. As shown in Table 2, the interlayer thickness of

237 C-S-H (I) shifts to a d-spacing value of around 1.283-1.298 nm, which is much higher than that

238 in pure AAS binders (around $1.250 \mathrm{~nm}[8,33]$ ). According to previous findings, the introduction

239 of large amounts of aluminum into the C-S-H structure can inflate the interlayer thickness by

240 decreasing the coherent domain [16]. This phenomenon is more evident in Figure 5 by

241 comparing the XRD patterns of C-S-H (I) in pure AAS and AAS with a small replacement of

242 FA-F activated by HN. This proves that there exists an interaction between FA-F and slag during

243 activation and geopolymerization process. In addition, Figure 5 shows that HN promotes the

244 formation of C-S-H (I) with a co-existence with C-S-H, while no strong evidence of C-S-H (I)

245 can be observed in NS- and LN-activated systems. This indicates that the nanostructure of

246 C-A-S-H formed in the binary FA-F/slag system is considerably affected by the activator type.

247 Besides, LN can significantly promote the generation of sodium calcium aluminum sulfate

248 hydrate (NCASH) phase (The source of sulfate comes from the composition of slag as shown in

249 Table 1). It is noticed that this sulfate-bearing phase gradually decomposes over time and

250 completely absent in $\mathrm{HN}$-activated mixtures, suggesting that sulfate-bearing phase is unstable in

251 high alkalinity or high $\mathrm{pH}$ environments.

252 
253 Figure 5 shows the XRD patterns for binary 20\% FA-F with $80 \%$ slag activated by various

254 solutions. First, consistent with the findings in Figure 4, LN solution promotes the extensive

255 formation of sulfate-bearing phase while HN promotes C-S-H (I). Additionally, a much stronger

256 peak corresponding to hydrotalcite-type phase is also observed in $\mathrm{HN}$-activated system, probably

257 indicating that hydrotalcite is preferably formed at high $\mathrm{pH}$.

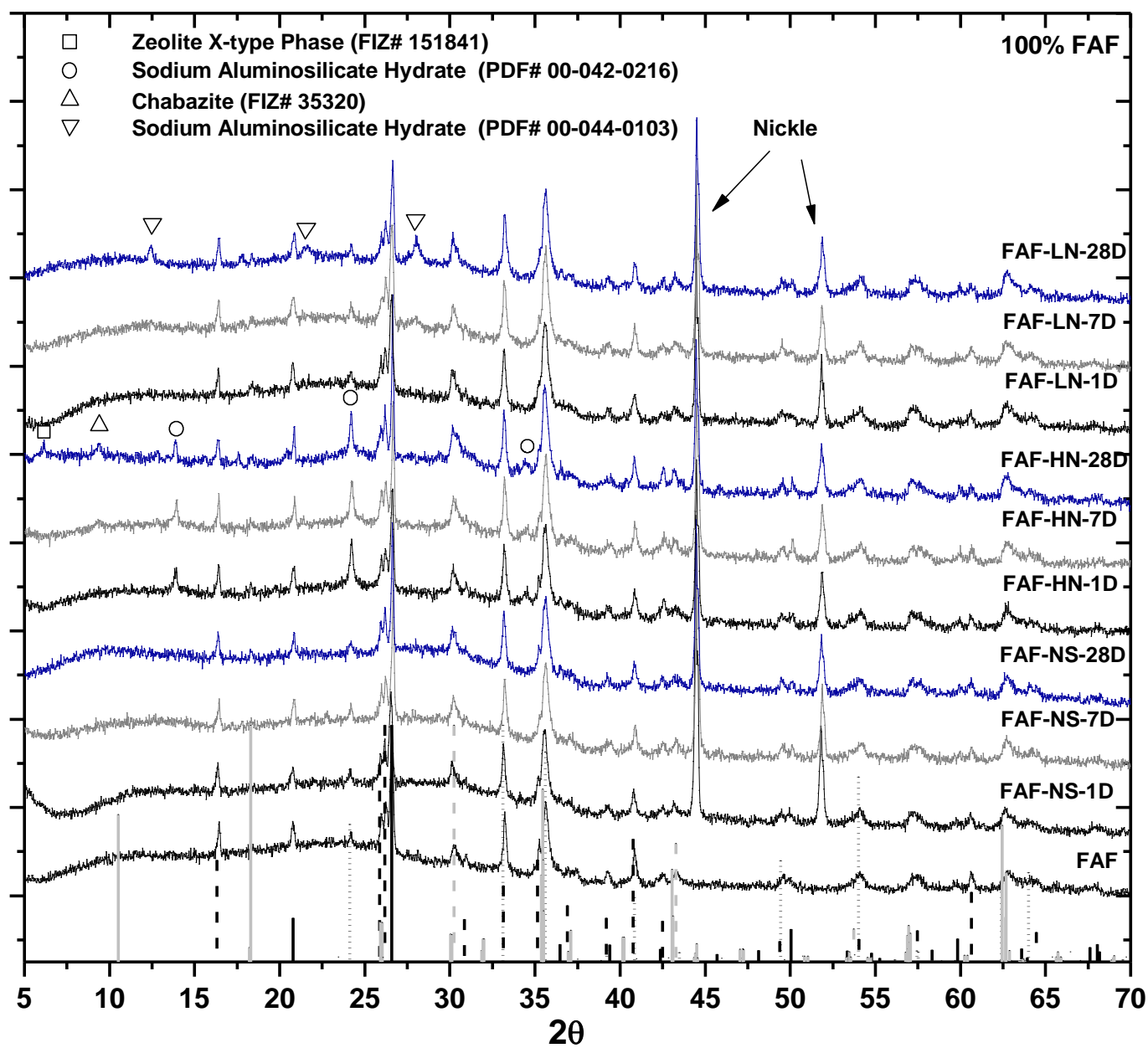

260 Figure $2 \mathrm{X}$-ray diffraction patterns of pure alkali-activated FA-F with various types of activators 


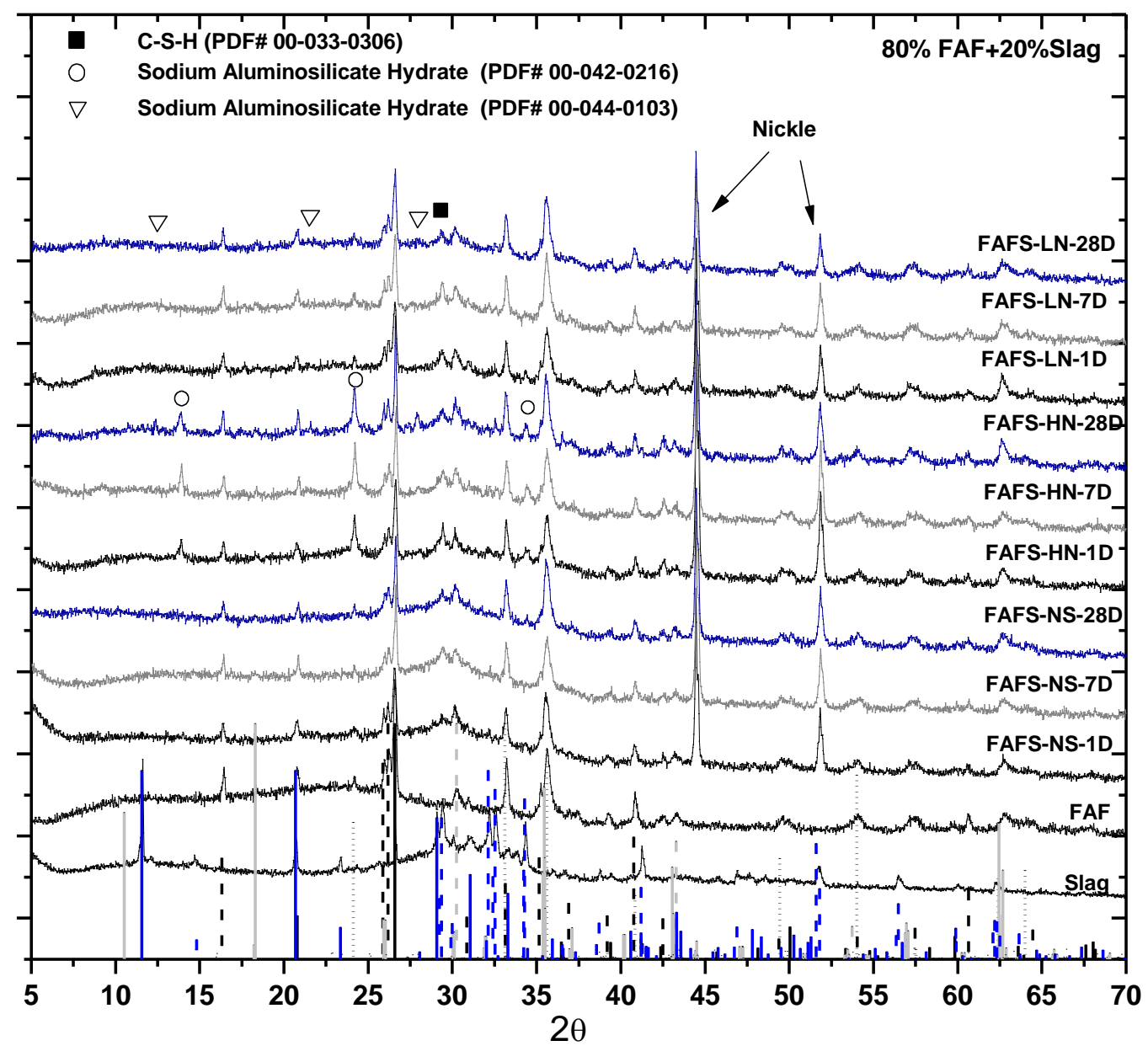

265 Figure 3 X-ray diffraction patterns of alkali-activated binary $80 \%$ FA-F and $20 \%$ slag with

266 various types of activators at different ages (i.e. 1, 7, and 28 Days). 


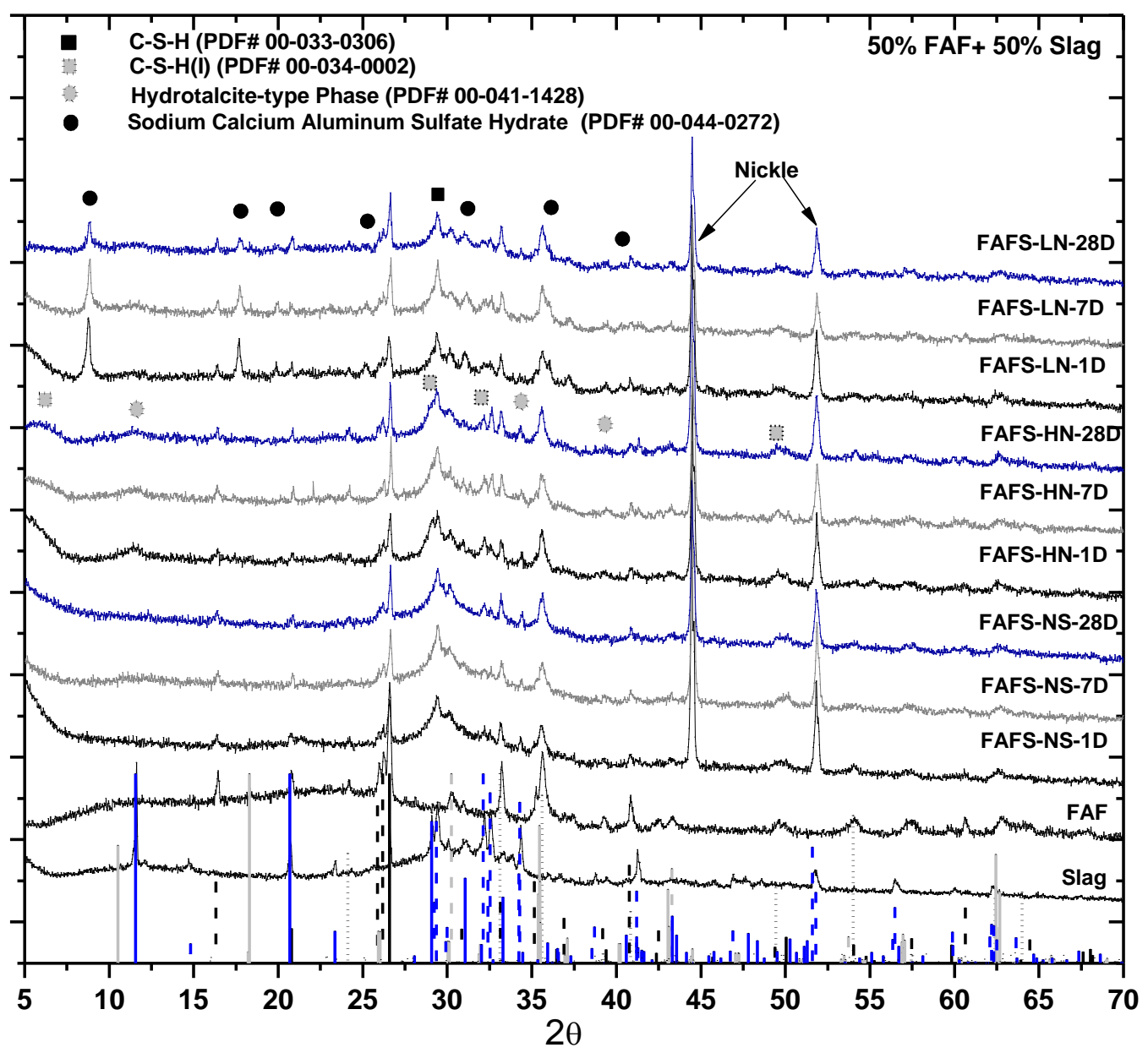

270 Figure 4 X-ray diffraction patterns of alkali-activated binary 50\% FA-F and 50\% slag with

271 various types of activators at different ages (i.e. 1, 7, and 28 Days). 


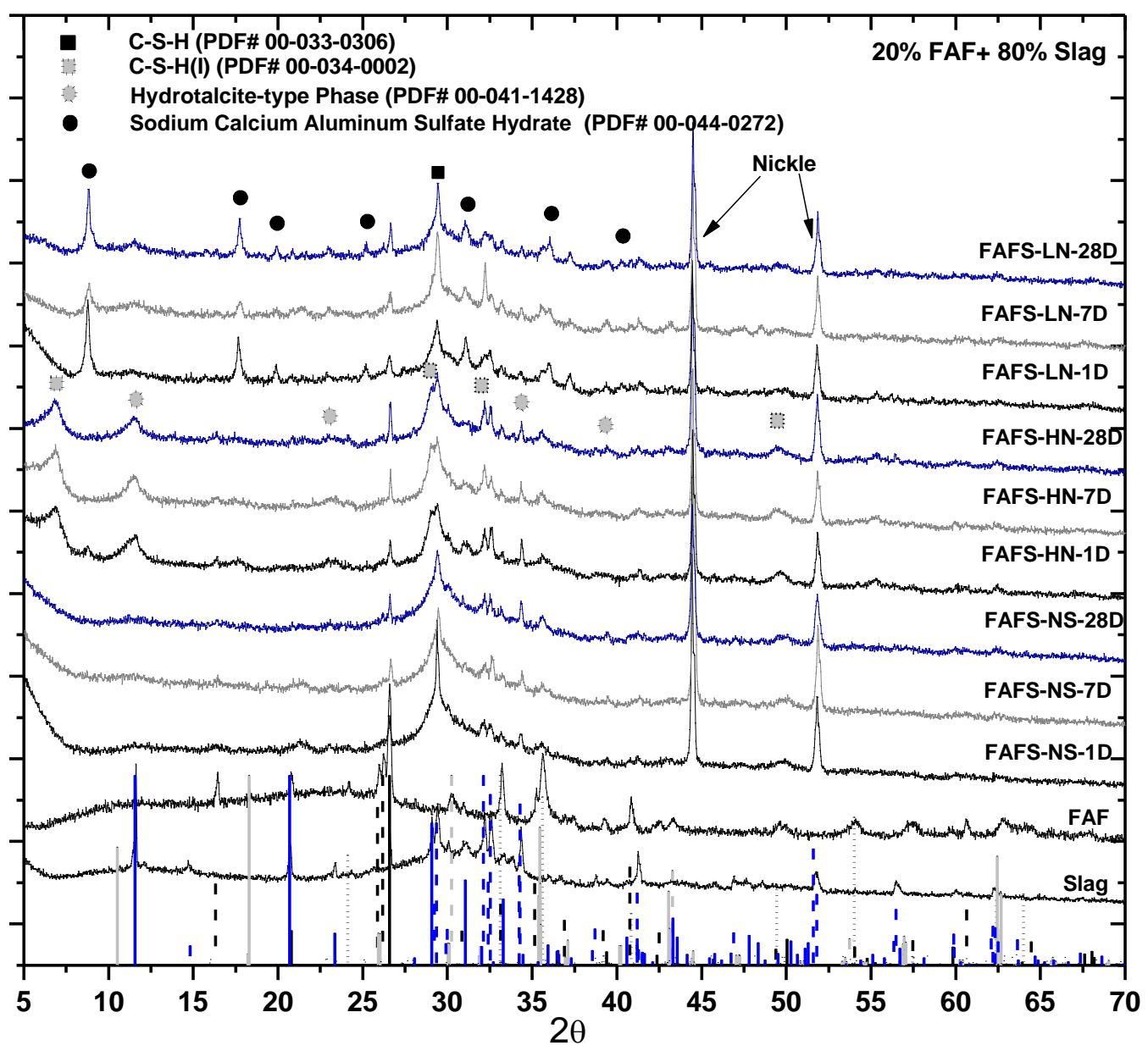

274 Figure 5 X-ray diffraction patterns of alkali-activated binary $20 \%$ FA-F and $80 \%$ slag with

275 various types of activators at different ages (i.e. 1, 7, and 28 Days).

278 Table 2 X-ray diffractometry data for identification of main peaks in binary FA-F/slag-based

279 geopolymer pastes

Observed d-Spacing in

this study $(\AA)$
Theoretical

Phase

$(\mathrm{h} \mathrm{k} \mathrm{l)}$ 


\begin{tabular}{|c|c|c|c|}
\hline 14.47 & Zeolite X-type Phase & 14.43 & $\left(\begin{array}{lll}1 & 1 & 1\end{array}\right)$ \\
\hline 9.36 & Chabazite & 9.32 & $\left(\begin{array}{lll}1 & 0 & 0\end{array}\right)$ \\
\hline $6.35-6.37$ & & 6.35 & $\left(\begin{array}{lll}1 & 1 & 0\end{array}\right)$ \\
\hline 3.67 & $\begin{array}{l}\text { Sodium Aluminosilicate Hydrate } \\
\qquad\left(\mathrm{Na}_{6}\left(\mathrm{AlSiO}_{4}\right)_{6} \cdot 4 \mathrm{H}_{2} \mathrm{O}\right)\end{array}$ & 3.66 & $\left(\begin{array}{lll}2 & 1 & 1\end{array}\right)$ \\
\hline $2.59-2.60$ & & 2.59 & $\left(\begin{array}{lll}2 & 2 & 2\end{array}\right)$ \\
\hline 7.09 & & 7.10 & $\left(\begin{array}{lll}1 & 1 & 0\end{array}\right)$ \\
\hline $4.10-4.11$ & $\begin{array}{l}\text { Sodium Aluminosilicate Hydrate } \\
\qquad\left(\mathrm{Na}_{1.4} \mathrm{Al}_{2} \mathrm{Si}_{3.9} \mathrm{O}_{11.5} \cdot \mathrm{H}_{2} \mathrm{O}\right)\end{array}$ & 4.10 & $\left(\begin{array}{lll}1 & 1 & 2\end{array}\right)$ \\
\hline $3.18-3.19$ & & 3.18 & $\left(\begin{array}{lll}3 & 1 & 0\end{array}\right)$ \\
\hline $3.03-3.04$ & Calcium Silicate Hydrate C-S-H & 3.04 & - \\
\hline 1.82 & $\left(\mathrm{Ca}_{1.5} \mathrm{SiO}_{3.5} \cdot \mathrm{xH}_{2} \mathrm{O}\right)$ & 1.82 & - \\
\hline $12.83-12.98$ & & 12.50 & $\left(\begin{array}{lll}0 & 0 & 2\end{array}\right)$ \\
\hline $3.06-3.07$ & Calcium-Silicate Hydrate C-S-H (I) & 3.07 & $\left(11^{*}\right)^{a}$ \\
\hline $2.78-2.80$ & $\left(\mathrm{CaO} \cdot \mathrm{SiO}_{2} \cdot \mathrm{H}_{2} \mathrm{O}\right)$ & 2.80 & $(20 *)^{2}$ \\
\hline $1.83-1.84$ & & 1.83 & $(02 *)^{2}$ \\
\hline 10.03 & & 10.03 & $\left(\begin{array}{lll}0 & 0 & 3\end{array}\right)$ \\
\hline 5.01 & & 5.01 & $\left(\begin{array}{lll}0 & 0 & 6\end{array}\right)$ \\
\hline 4.46 & $\begin{array}{l}\text { Sodium calcium aluminum sulfate hydrate } \\
\qquad\left(\mathrm{NaCa}_{4} \mathrm{Al}_{2} \mathrm{O}_{6}\left(\mathrm{SO}_{4}\right)_{1.5} \cdot 15 \mathrm{H}_{2} \mathrm{O}\right)\end{array}$ & 4.45 & $\left(\begin{array}{lll}1 & 0 & 3\end{array}\right)$ \\
\hline 3.53 & & 3.53 & $\left(\begin{array}{lll}1 & 0 & 6\end{array}\right)$ \\
\hline 2.88 & & 2.87 & $\left(\begin{array}{lll}1 & 1 & 0\end{array}\right)$ \\
\hline
\end{tabular}


Note: a: hk* denotes a band head given by an essentially two-dimensional lattice

\subsection{Rietveld semi-quantitative- $X$-ray diffraction analysis}

284 Table 3 shows the results of Rietveld quantitative analysis in binary FA-F/slag-based geopolymer

285 paste samples. Most of the phases are amorphous, accounting for about 71.1\% 98.6\%,

286 depending on the age, activator type/dosage and FA-F/slag ratio. It should be noted that it is

287 impossible to differentiate the vitreous unhydrated phases from amorphous hydrated products (i.e.

288 C-A-S-H and N-A-S-H gels) based solely on the Rietveld method. It can be seen that the

$289 \mathrm{HN}$-activated materials have up to $10.1 \%$ crystalline C-S-H (I), 3.3\% crystalline C-S-H, $1.7 \%$

290 crystalline N-A-S-H, and $13.7 \%$ hydrotalcite, while $\mathrm{LN}$ solution can have up to $10.6 \%$

291 crystalline C-S-H, 13.4\% NCA $\underline{\mathrm{S}} \mathrm{H}$, and 2.7\% hydrotalcite. In addition, the relative proportion of 292 crystalline C-S-H gel increases from $1 \%$ to about $11 \%$, with increasing slag portion from 0.2 to 
2930.8 for $\mathrm{NH}$-activated system. The percentage of hydrotalcite also increases with increasing 294 relative portion of slag, especially at high $\mathrm{pH}$ binders. The Rietveld quantitative analysis results 295 are consistent with the findings reported in Section 3.1.

298 Table 3 Rietveld quantitative phase analysis of binary slag and Class F fly ash-based geopolymer 299 samples at different ages (by mass \%) ${ }^{\mathrm{d}}$

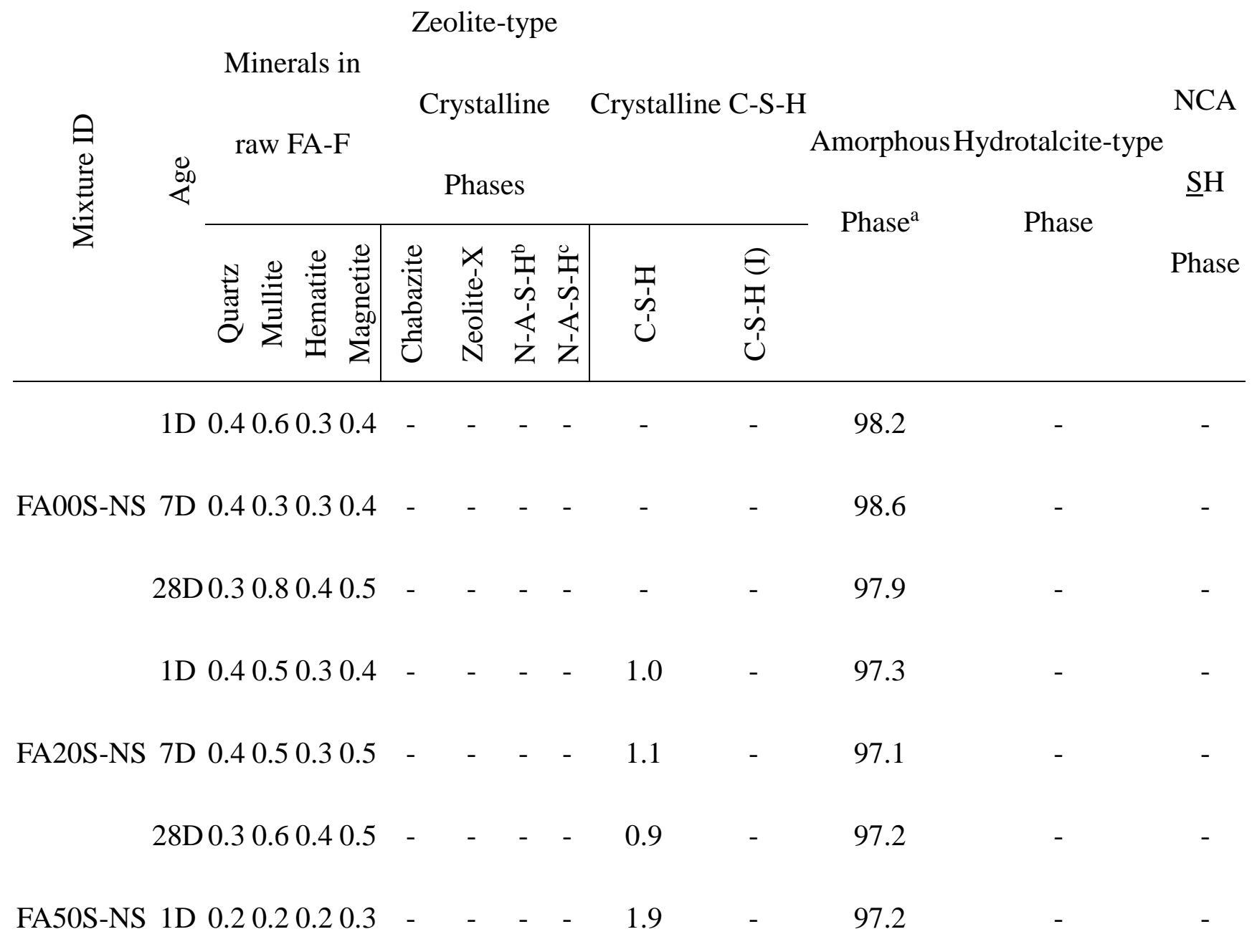




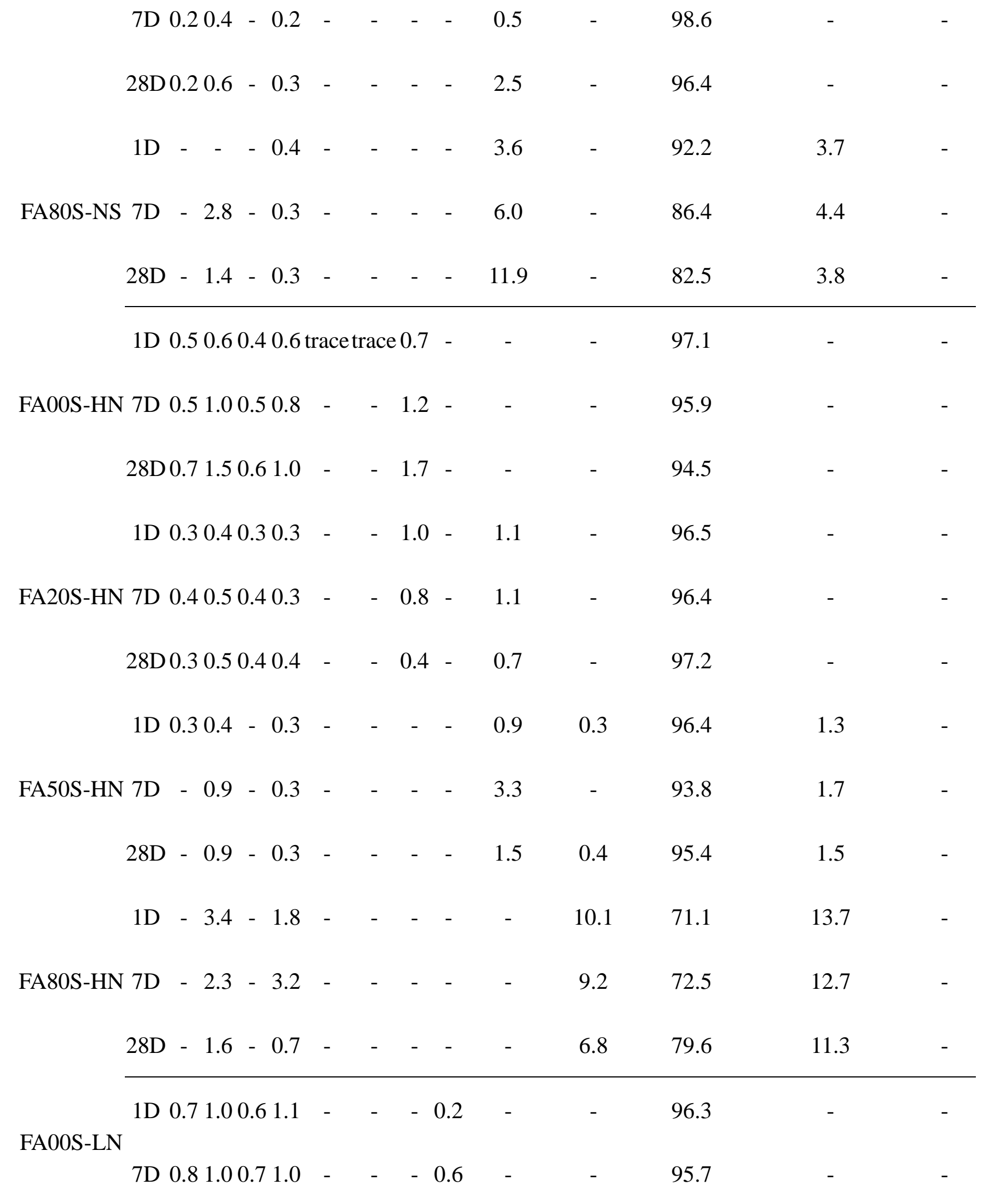


28D $0.60 .80 .80 .8 \quad-\quad-\quad-\quad \begin{array}{llllll}2.0 & - & - & - & 94.9\end{array}$

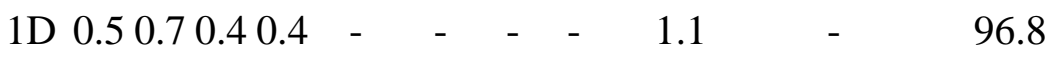

FA20S-LN 7D $0.50 .70 .40 .4 \quad-\quad-\quad \begin{array}{llllllll}0 & 0 & 0.8 & - & - & 97.1\end{array}$ 28D $0.60 .80 .60 .5 \quad-\quad-\quad-\quad-\quad \begin{array}{lllll}0 & - & 1.3 \quad & - & 96.1\end{array}$

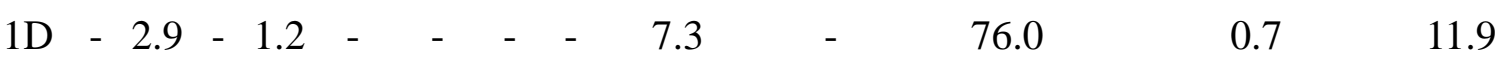

$\begin{array}{llllllllllllllll}\text { FA50S-LN 7D } & - & 5.6 & - & 1.8 & - & - & - & - & 5.8 & - & 71.4 & 2.1 & 13.4\end{array}$

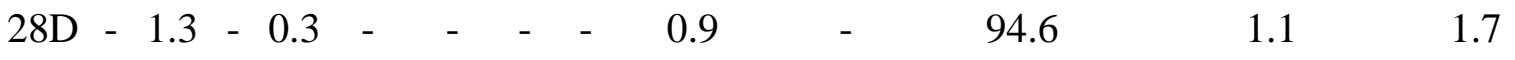

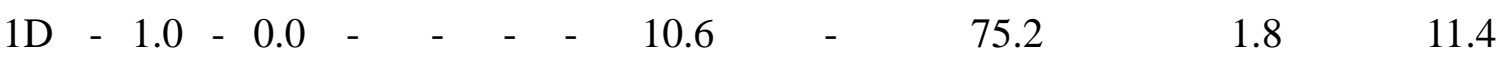

$\begin{array}{llllllllllllll}\text { FA80S-LN 7D } & - & 0.4 & - & 0.0 & - & - & - & - & 5.9 & 0.2 & 87.0 & 2.7 & 3.7\end{array}$
$28 \mathrm{D}-1.1-0.3$
4.2
82.6
2.4
9.3

300 Notes: a: It includes both the amorphous structures in unhydrated raw materials and the

301 generated amorphous structures in hydrated phases, mainly N-A-S-H gel and C-A-S-H gel.

302 b: It is the detected sodium aluminosilicate hydrate $\left(\mathrm{Na}_{6}\left(\mathrm{AlSiO}_{4}\right)_{6} \cdot 4 \mathrm{H} 2 \mathrm{O}\right)$.

$303 \mathrm{c}$ : It is the detected sodium aluminosilicate hydrate $\left(\mathrm{Na}_{1.4} \mathrm{Al}_{2} \mathrm{Si}_{3.9} \mathrm{O}_{11.5} \cdot \mathrm{H} 2 \mathrm{O}\right)$

$304 \mathrm{~d}$ : The estimated errors for the Rietveld semi-quantitative analysis are less than $\pm 5 \%$.

307 Figures 6-8 show the SEM-BSE images of polished alkali-activated FA-F/slag-based geopolymer

308 paste samples at 28 days. It can be seen that the addition of slag considerably modifies the 
309 microstructure of FA-F-based geopolymer by reducing coarse pores and homogenizing

310 morphology, which is in agreement with the previous research [20, 34]. Additionally, activator

311 type/dosage also shows a significant influence on the microstructural characteristics of the

312 binders. The use of NS as a activator results in a much homogenous and denser microstructure

313 regardless of the $\mathrm{FA}-\mathrm{F} / \mathrm{slag}$ ratio, which supports the previous findings that $\left[\mathrm{SiO}_{2}\right] \mathrm{aq}$ can

314 homogenize the microstructure [8, 20]. It can also be noticed that although both slag and

$315\left[\mathrm{SiO}_{2}\right]$ aq tend to densify the microstructure as shown in SEM, their mechanisms of influence are

316 different. It is reasonable to deduce that it is the calcium dissolved from slag that makes slag

317 different than [SiO2]aq. Previous research regarding the role of externally-added

318 calcium-enriched components on microstructural modification of FA-F-based geopolymer are

319 available, which generally argue that calcium from slag can promote the generation of C-A-S-H

320 gels, which reduces the setting time and densifies the microstructure [4]. This argument is also

321 supported by the changes in the chemical composition of the hydrated phases as discussed in the

322 following section. 


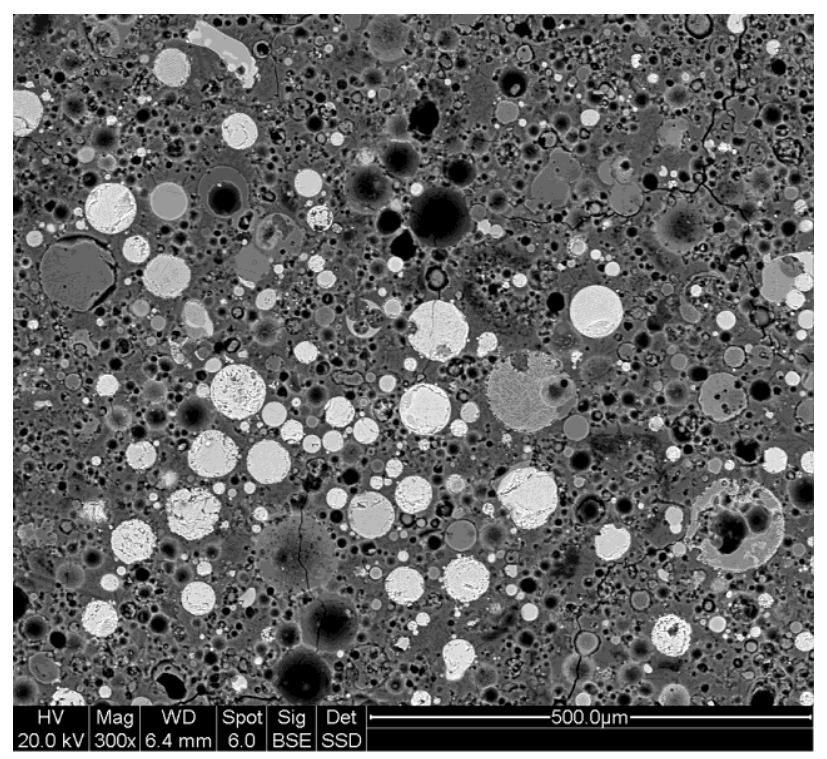

(a)

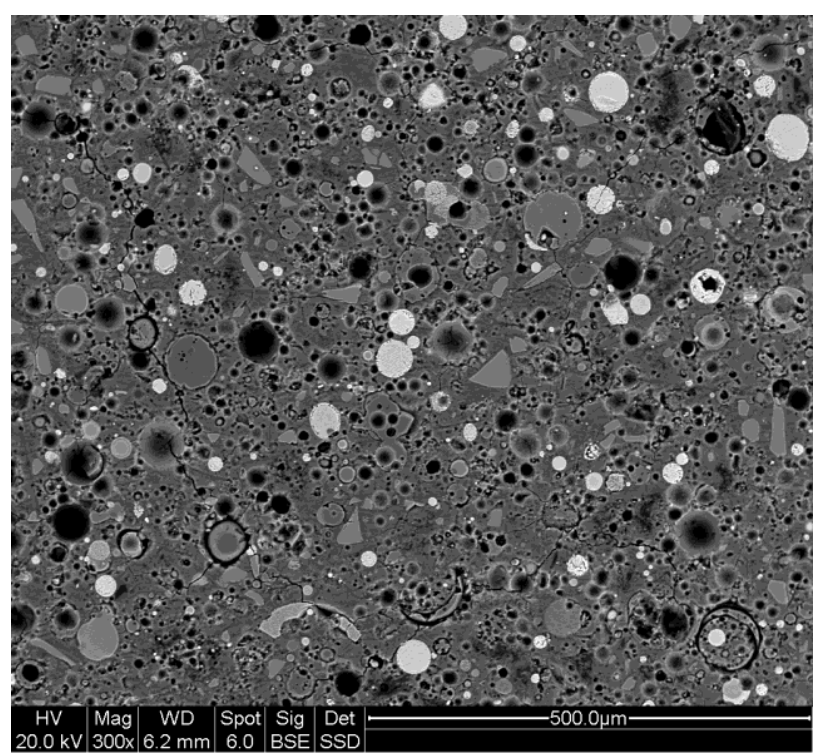

(b)

326

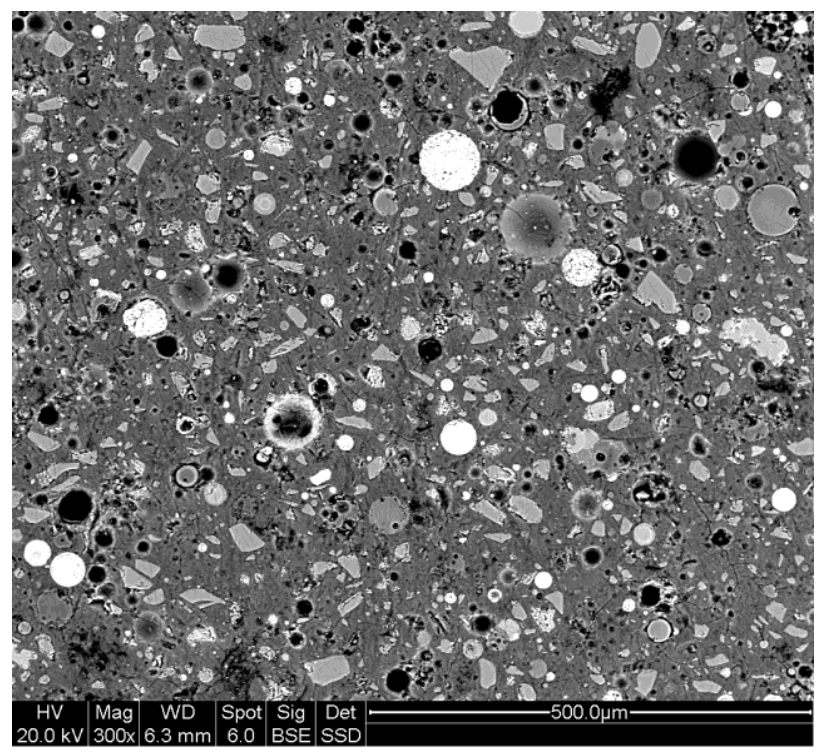

(c)

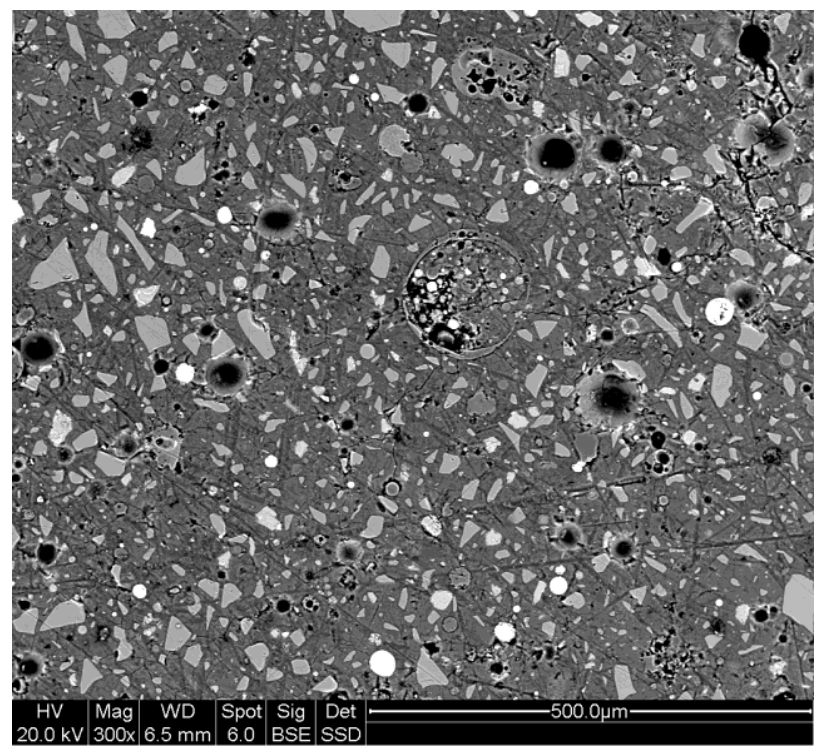

(d)

329 Figure 6 SEM-BSE images on polished binary FA-F/slag samples activated by NS solutions

330 (a) 100\%FA-FA; (b) 80\%FA-F and 20\%slag; (c) 50\%FA-F and 50\%slag; (d) 20\%FA-F and $33180 \%$ slag 
333

334

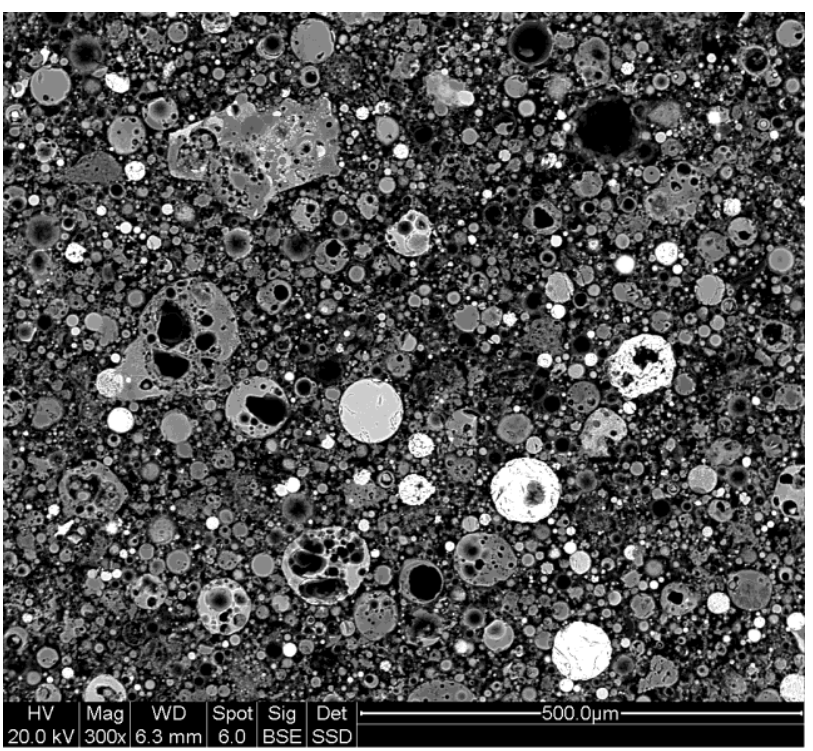

(a)

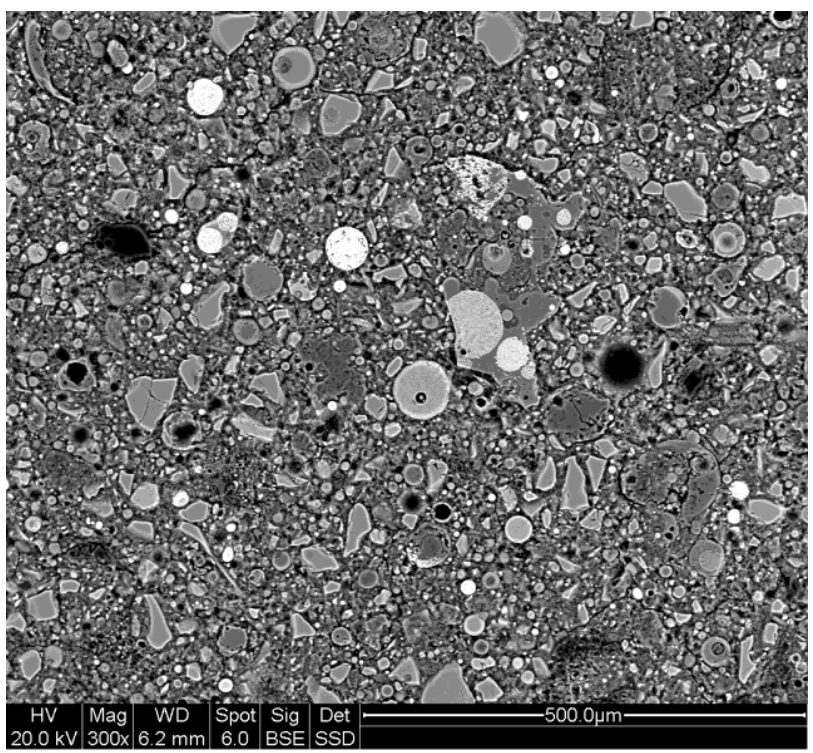

(c)

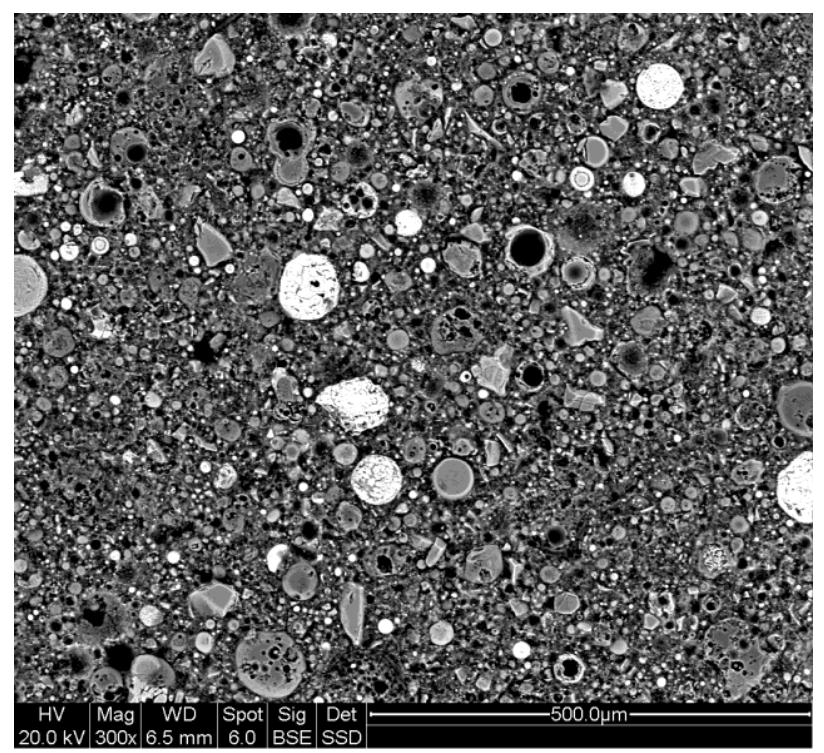

(b)

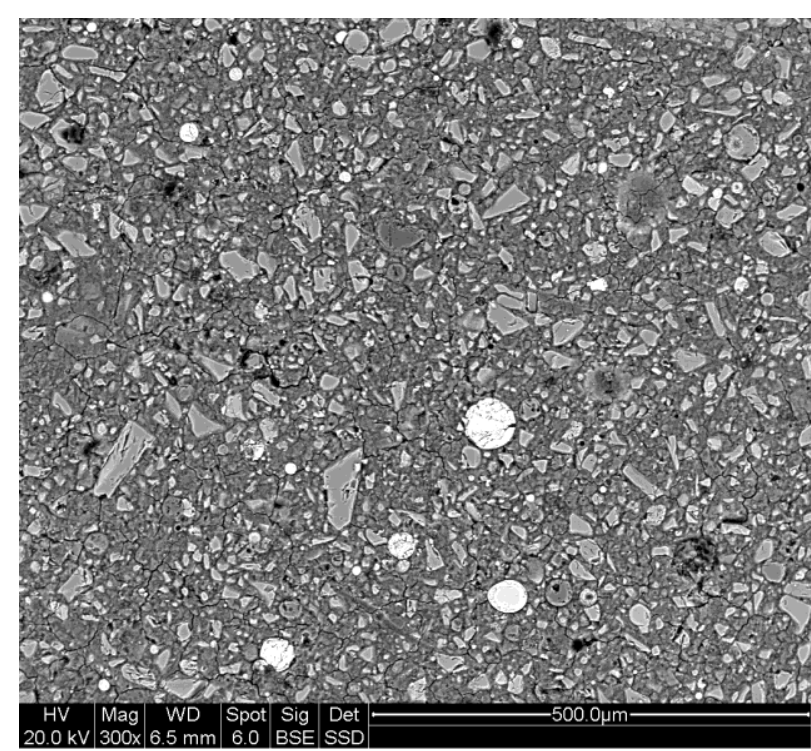

(d)

337 Figure 7 SEM-BSE images on polished binary FA-F/slag samples activated by HN solutions

338 (a)100\%FA-FA; (b) 80\%FA-F and 20\%slag; (c) 50\%FA-F and 50\%slag; (d) 20\%FA-F and $33980 \%$ slag 


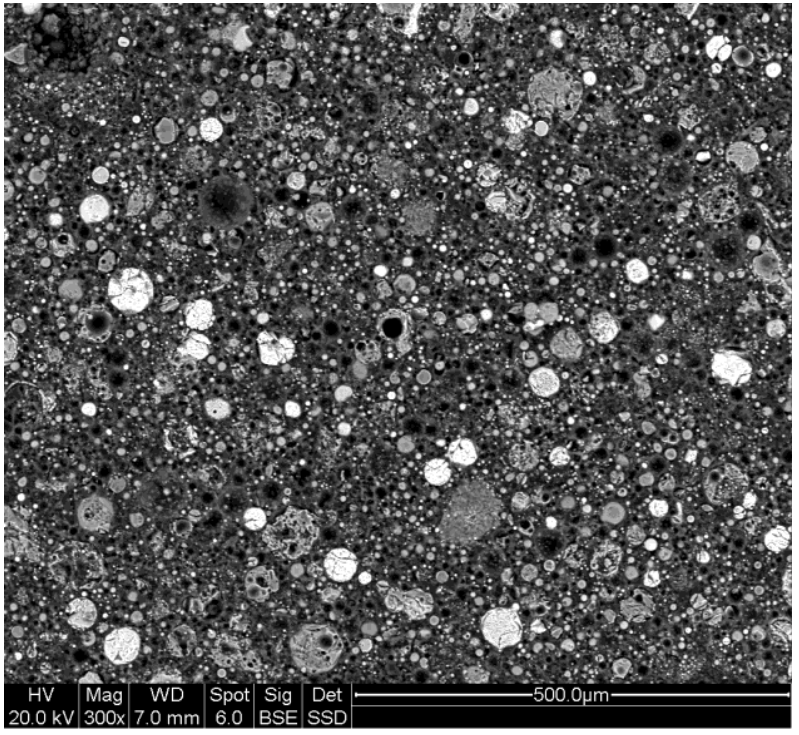

(a)

\section{3}

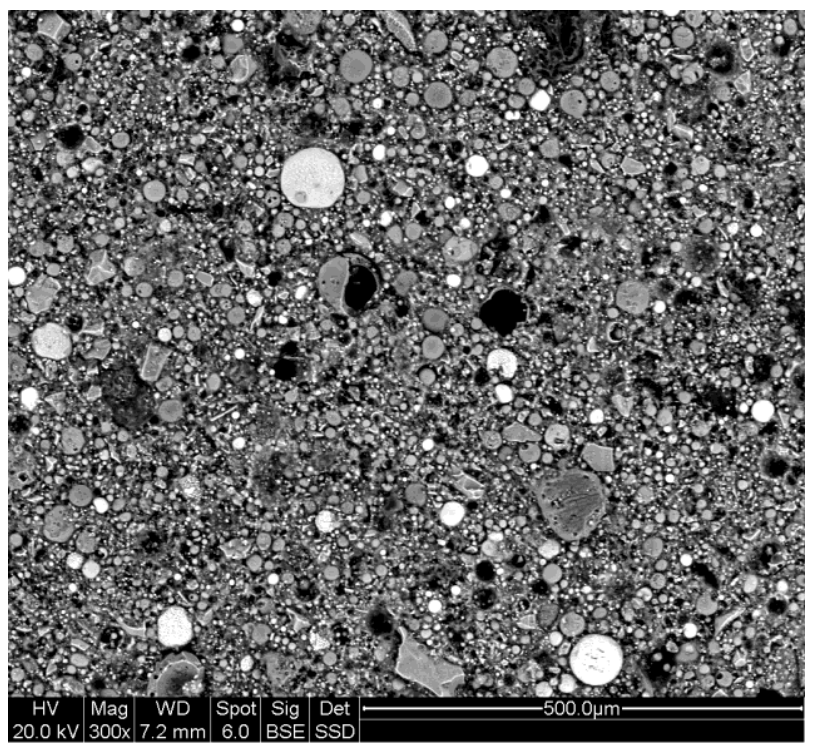

(c)

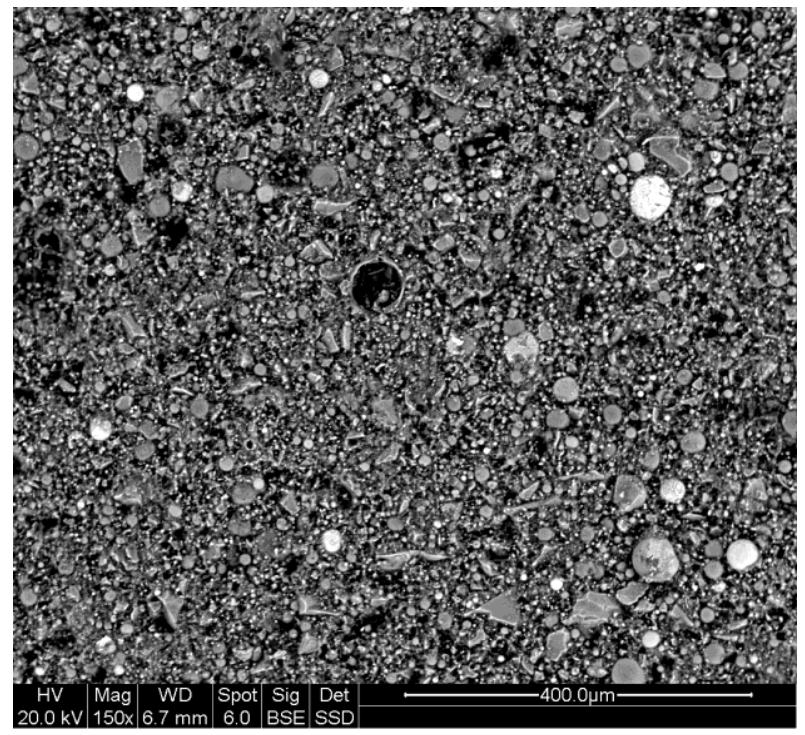

(b)

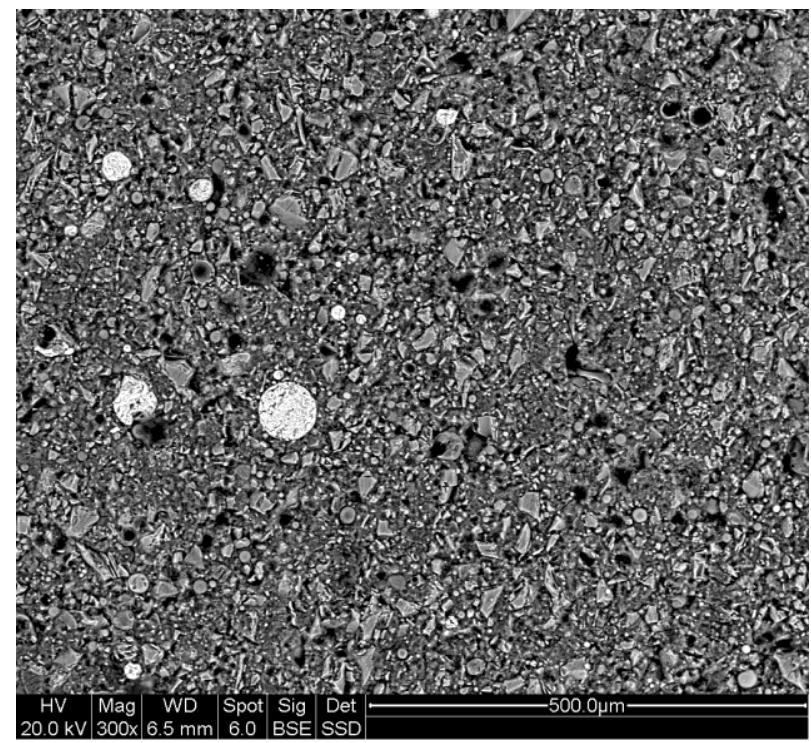

(d)

346 Figure 8 SEM-BSE images on polished binary FA-F/slag samples activated by LN solutions (a)

347 100\%FA-FA; (b) 80\%FA-F and 20\%slag; (c) 50\%FA-F and 50\%slag; (d) 20\%FA-F and 80\%slag 
351 Figures 9-11 show the $\mathrm{SiO}_{2}-\mathrm{CaO}-\mathrm{Al}_{2} \mathrm{O}_{3}-\mathrm{H}_{2} \mathrm{O}$ and $\mathrm{SiO}_{2}-\mathrm{Na}_{2} \mathrm{O}-\mathrm{Al}_{2} \mathrm{O}_{3}-\mathrm{H}_{2} \mathrm{O}$ ternary phase diagrams

352 for the hydration products formed in the matrix of FA-F/slag-based geopolymer samples

353 activated by NS, HN, and LN solutions, respectively. Considering the large spot size of EDS, the

354 measured chemical composition may represent a mixture of C-A-S-H, N-A-S-H, N-C-A-S-H,

355 with other minor phases. The $\mathrm{SiO}_{2}-\mathrm{CaO}-\mathrm{Al}_{2} \mathrm{O}_{3}-\mathrm{H}_{2} \mathrm{O}$ diagram can be segmented into various

356 regions, each of which represents a chemical boundary for each phase. For example, the Region I

357 represents the N-A-S-H-rich region, in which the $0.08<\mathrm{Al} / \mathrm{Si}<0.5$ and $0<\mathrm{Ca} / \mathrm{Si}<0.3$ in N-A-S-H

358 [35]. Similarly, Region II is where C-A-S-H is the primary phase. It is observed that the

359 incorporation of slag can drastically alter the chemical composition of the gels formed in the

360 matrix, regardless of the activator type. With the increase of slag dosage, the chemical

361 composition of the hydration products moves from Region I towards Region II. It demonstrates

362 that C-A-S-H is formed gradually as slag replacement increases, which is consistent with the

363 XRD results. On the other hand, the statistical distribution of the chemical composition as shown

364 in Figure 12 box plots also shows that mean $\mathrm{Ca} / \mathrm{Si}$ and $\mathrm{Na} / \mathrm{Al}$ ratios in the hydrated phases tend

365 to increase, while keeping $\mathrm{Al} / \mathrm{Si}$ approximately constant as slag replacement increases. This is

366 reasonable since raw slag is much richer in calcium and contains less alumina than FA-F.

367 According to the $\mathrm{SiO}_{2}-\mathrm{Na}_{2} \mathrm{O}-\mathrm{Al}_{2} \mathrm{O}_{3}-\mathrm{H}_{2} \mathrm{O}$ ternary diagram in Figs. 9-11, almost all FA-F-rich

368 samples are located in the same region, which indicates the relative stability of alkali content in 
369 the various gels. However, with the increase of slag, all points move slightly towards alkali-rich

370 region, which is probably because of the reduced Si content in the formed gels.

372 The influence of activator on the chemical composition of FA-F/slag-based geopolymer can also 373 be observed. First of all, $\mathrm{NaOH}$-activated samples have higher average $\mathrm{Ca} / \mathrm{Si}$ and $\mathrm{Al} / \mathrm{Si}$ ratios, as

374 well as more heterogeneous chemical distribution, compared with NS-activated samples (see

375 Figure 12). It implies that this highly reactive [SiO2]aq incorporates into the geopolymerization

376 process and depresses the precipitation of zeolite crystals, as indicated in XRD results. The

$377 \mathrm{SiO}_{2}-\mathrm{CaO}-\mathrm{Al}_{2} \mathrm{O}_{3}-\mathrm{H}_{2} \mathrm{O}$ diagram shows no points located in the Region II for small slag/FA-F ratio

378 when activated by sodium silicate. It may indicate that when excess [SiO2]aq is supplied,

379 N-A-C-S-H is preferentially formed rather than C-A-S-H, which agrees with previous research

380 [20]. While activated by sodium hydroxide, $\mathrm{SiO}_{2}-\mathrm{CaO}-\mathrm{Al}_{2} \mathrm{O}_{3}-\mathrm{H}_{2} \mathrm{O}$ diagram demonstrates that

381 C-A-S-H can form occasionally in the matrix. However, the structure similarity and difference

382 between N-A-C-S-H and C-A-S-H needs further investigation. On the other hand, LN-activated

383 hydration products have higher $\mathrm{Ca} / \mathrm{Si}$ ratios and more heterogeneous chemical distribution than

$384 \mathrm{HN}$-activated samples, although both of them are [SiO2] aq-free in activator. It likely indicates

385 that lower $\mathrm{pH}$ promotes calcium dissolution from slag, which is well established for $\mathrm{Ca}(\mathrm{OH})_{2}$

386 [36], and potentially increases the relative proportion of C-A-S-H gels. This may be the reason

387 why FA-F/slag binary systems with lower pore solution $\mathrm{pH}$ have shorter setting times compared

388 to the one with more alkaline pore solutions [37]. 
390 Figure 13 shows the Line EDS results for the elemental distribution between two randomly 391 selected semi-hydrated FA-F and slag particles for FA50S activated by NS, HN, and LN,

392 respectively. In case of NS-activated sample, it is interesting to notice that there exists a reaction

393 rim around the FA-F particle. The chemical analysis indicates a significant reduction in the $\mathrm{Si}$

394 content in this reaction rim compared to unhydrated FA-F, which may indicate that considerable

395 amount of $\mathrm{Si}$ is dissolved from FA-F into the matrix. Similar findings are observed in the

$396 \mathrm{HN}$-activated system. In addition, the $\mathrm{Ca}$ dissolved from slag considerably increases the $\mathrm{Ca}$

397 concentration around unhydrated FA-F in comparison to the bulk composition of raw FA-F, and

398 probably incorporates into geopolymerization. Analogously, the Al from FA-F can also affect the

399 hydration of slag by increasing the supply of alumina, as confirmed by XRD in Figures 4 and 5.

400 In case of $\mathrm{NaOH}$-activated samples, the results indicate a gradual dissolution of $\mathrm{Ca}, \mathrm{Al}$ and $\mathrm{Mg}$

401 from raw slag to the matrix to form hydrated phases, while a sudden decrease in $\mathrm{Si}$ and $\mathrm{Al}$

402 around FA-F particles. The influential range of dissolved FA-F or slag is merely the limit of

403 aqueous chemical environments around itself, which results in a heterogeneous and localized

404 chemical composition in matrix. It probably also indicates a different reaction process of alkaline

405 activation between FA-F and slag.

406

407

408

3.5 Interaction between slag and FA-F 
410 Combined with XRD, SEM/EDS findings confirm the existence of an interaction between FA-F

411 and slag during activation or geopolymerization process. This interaction mechanism is primarily

412 reflected in three aspects for a certain type of activator:

414 (1) Modifying the structure and composition of hydrated phases; for instance, the C-A-S-H in

415 pure AAS is modified with a change in lattice parameters even after a small dosage of FA-F 416 loading.

418 (2) Explicitly depressing or triggering the formation of some crystalline phases; for instance, the

419 early age precipitation of zeolite-type phases in FA-F-based geopolymer can be suppressed or 420 delayed with the addition of slag. This is probably because that calcium from slag can

421 incorporate into the geopolymerization by reacting with $\mathrm{N}-\mathrm{A}-\mathrm{S}-\mathrm{H}$ to form $\mathrm{N}-(\mathrm{C})-\mathrm{A}-\mathrm{S}-\mathrm{H}$,

422 resulting in a heterogeneous chemical distribution and inhibiting zeolite crystallization. As

423 further attacked by calcium, N-(C)-A-S-H gels can possibly transform to C-A-S-H gel, since it

424 was reported that calcium can substitute alkalis due to its higher affinity to silicon [38, 39].

426 (3) Influencing spatial heterogeneity of composition distribution in microstructure; for instance,

427 increasing slag proportion in the mixture seems to increase the degree of heterogeneity of $\mathrm{Ca} / \mathrm{Si}$

428 ratio in hydrated phases. It indicates that the interaction between FA-F and slag occurs locally 
429 rather than uniformly. In other words, the interaction mechanism between raw materials is more

430 likely due to interaction and reaction of dissolved chemical elements, which is further influenced

431 by the surrounding aqueous environment. The dissolution of FA-F/slag is time-dependent,

432 indicating that the elemental concentration varies around the unhydrated particles, and the nature

433 and composition of the hydrated gels in the matrix are subjected to evolution as hydration

434 continues. There may exist local phase transformation among N-A-S-H, N(-C)-A-S-H,

435 (N-)C-A-S-H, and C-A-S-H, depending on the FA-F/slag ratio, dissolution/diffusion kinetics,

436 solubility of phases, nature of activator, and local aqueous chemical environment.

\subsubsection{Influence of alkaline activator}

439 The interaction between FA-F and slag is strongly affected by activator type and dosage, which

440 is also primarily reflected in analogous aspects, namely, chemistry, structure and kinetics. First of

441 all, the nanostructure or chemical composition of the hydrated gels, as well as the selective

442 formation of other by-products, (e.g. portlandite, sulfate-bearing phases, and hydrotalcite-type

443 phases), is dependent on activators. For instance, various types of C-A-S-H and N-A-S-H gels

444 can be observed if different activators are used. Low $\mathrm{pH}$ solutions promote the formation of

445 C-S-H while high $\mathrm{pH}$ promotes C-S-H (I), and they have different nanostructures. Secondly,

446 heterogeneity of spatial distribution of composition in microstructure is activator-dependent. For

447 example, as shown in Figure 12, NS-activated samples essentially have more chemically

448 homogenous distributions, which is probably because [ $\mathrm{SiO} 2] \mathrm{aq}$ can delay the hydration by 
449 prolonging active FA-F/slag dissolution/diffusion kinetics. Similar observation can be noticed in

450 AAS, in which [SiO2] aq can distribute nucleation sites homogenously at early ages, resulting in

451 slag taking longer time to reach 'diffusion-controlled' hydration period $[8,40]$.

452

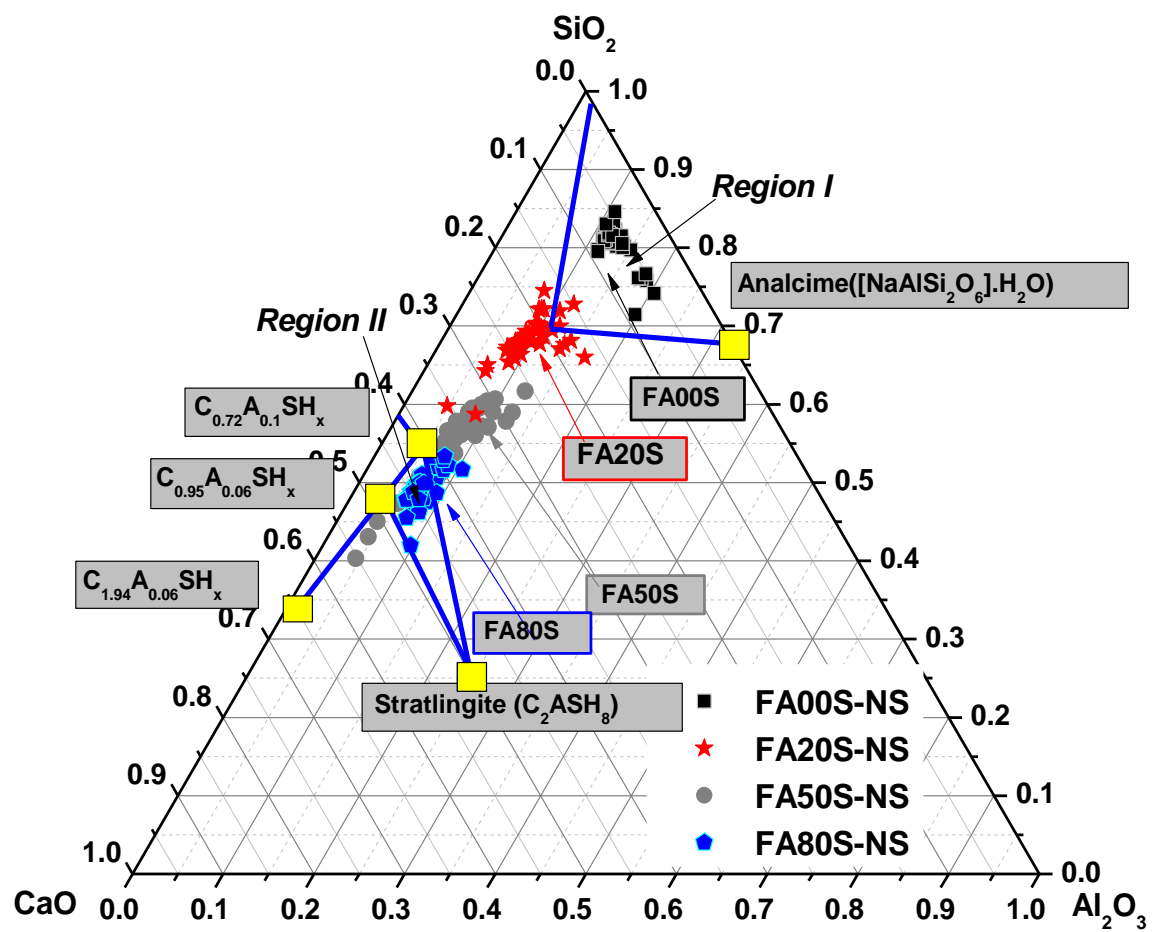

453 


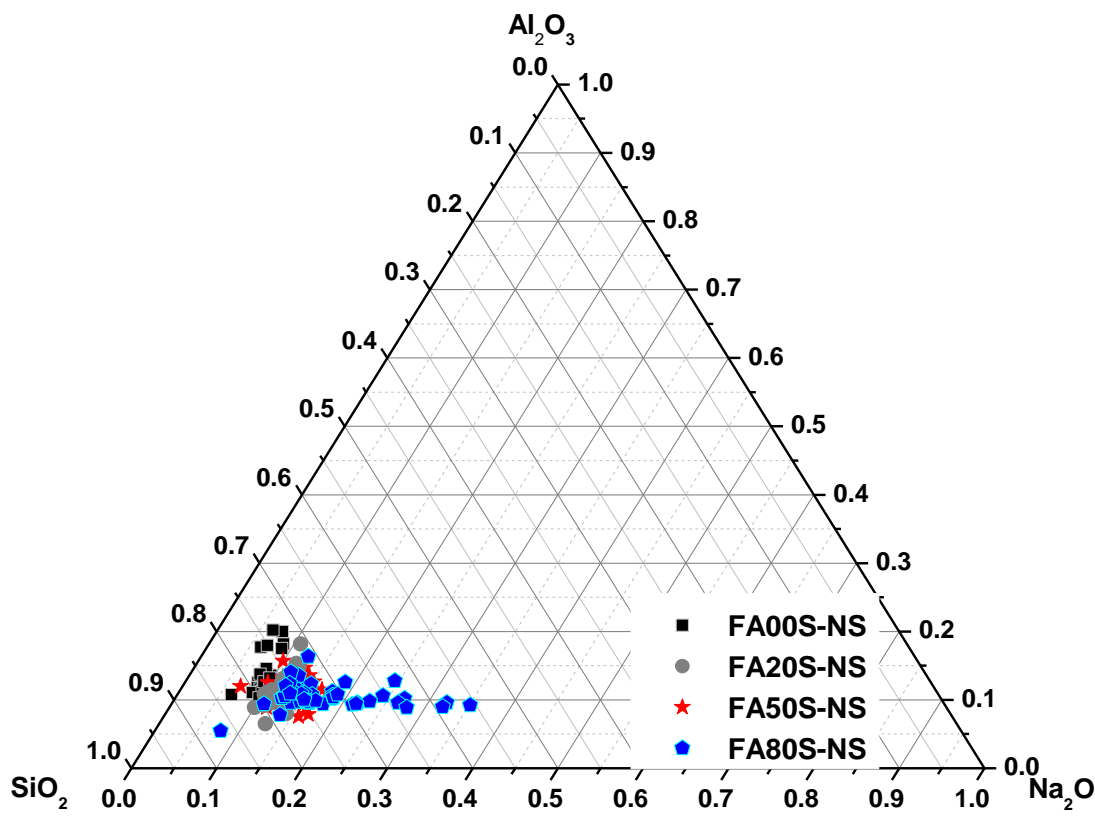

(b)

457 Figure 9 EDS microanalysis of hydration products formed in binary FA-F and slag samples with 458 various FA-F/slag ratios activated by $\mathrm{NS}$ projected on the (a) $\mathrm{CaO}-\mathrm{SiO}_{2}-\mathrm{Al}_{2} \mathrm{O}_{3}-\mathrm{H}_{2} \mathrm{O}$ ternary 459 system diagram (b) $\mathrm{SiO}_{2}-\mathrm{Na}_{2} \mathrm{O}-\mathrm{Al}_{2} \mathrm{O}_{3}-\mathrm{H}_{2} \mathrm{O}$ ternary diagram 

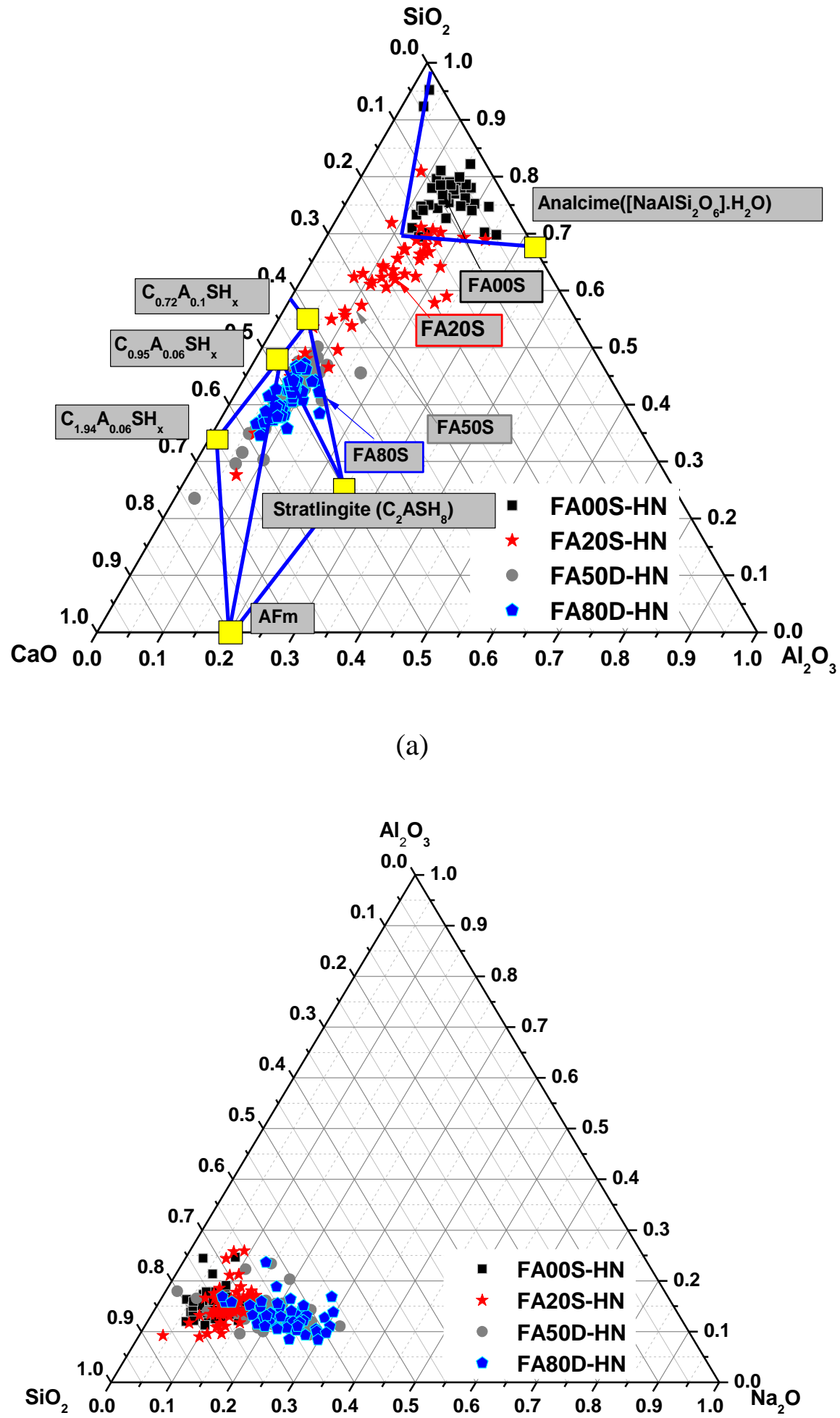

(b)

464 Figure 10 EDS microanalysis of hydration products formed in binary FA-F and slag samples 
465 activated $\mathrm{HN}$ with various $\mathrm{FA}-\mathrm{F} / \mathrm{slag}$ ratios projected on the (a) $\mathrm{CaO}-\mathrm{SiO}_{2}-\mathrm{Al}_{2} \mathrm{O}_{3}-\mathrm{H}_{2} \mathrm{O}$ ternary 466 system diagram (b) $\mathrm{SiO}_{2}-\mathrm{Na}_{2} \mathrm{O}-\mathrm{Al}_{2} \mathrm{O}_{3}-\mathrm{H}_{2} \mathrm{O}$ ternary diagram

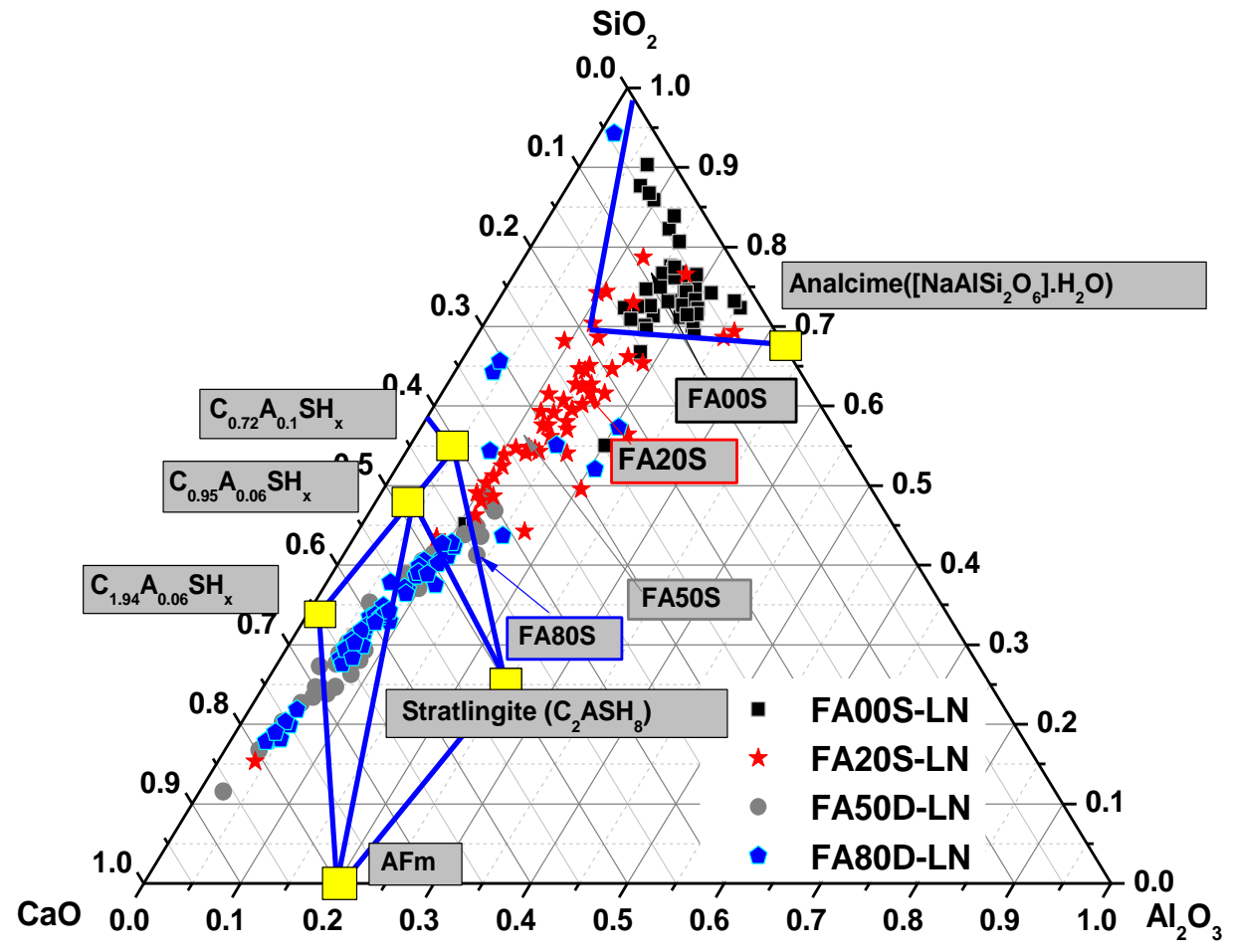




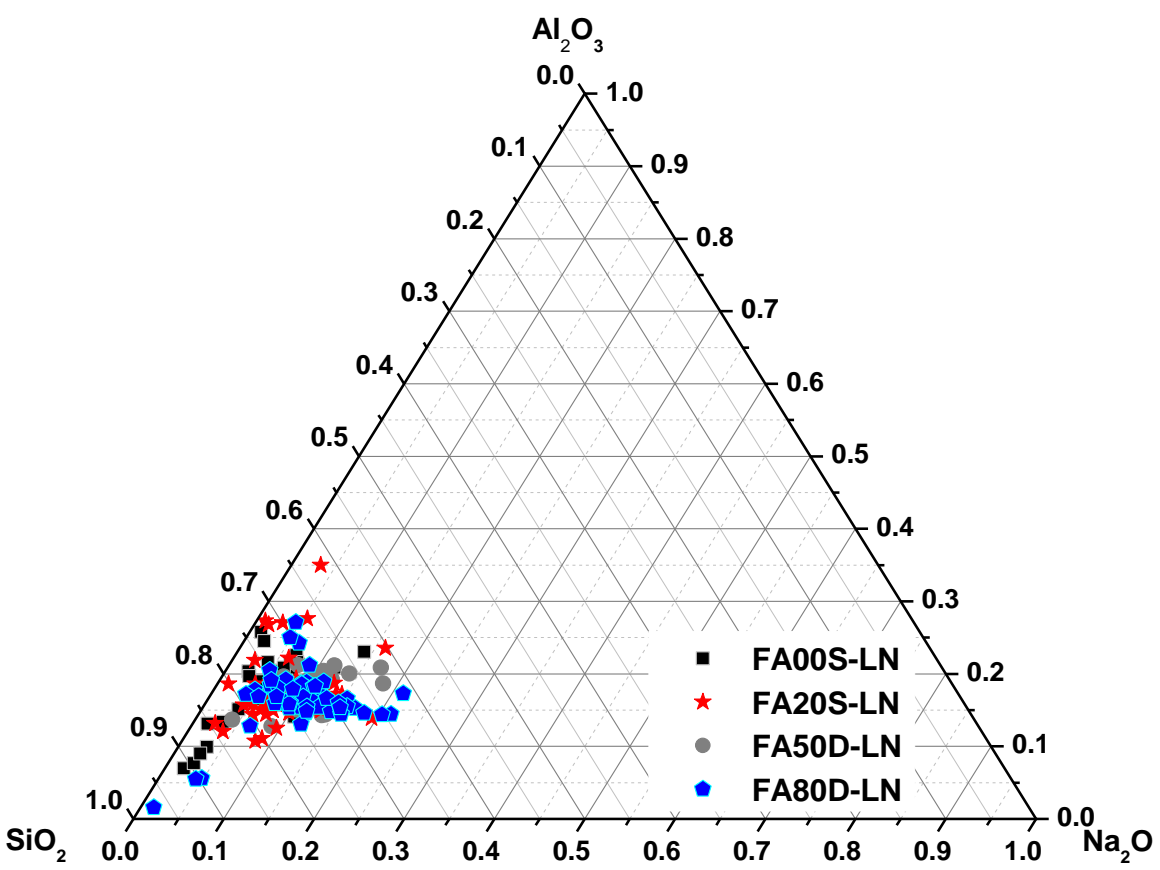

(b)

471 Figure 11 EDS microanalysis of hydration products formed in binary FA-F and slag samples

472 activated $\mathrm{LN}$ with various $\mathrm{FA}-\mathrm{F} / \mathrm{slag}$ ratios projected on the (a) $\mathrm{CaO}-\mathrm{SiO}_{2}-\mathrm{Al}_{2} \mathrm{O}_{3}-\mathrm{H}_{2} \mathrm{O}$ ternary

473 system diagram (b) $\mathrm{SiO}_{2}-\mathrm{Na}_{2} \mathrm{O}-\mathrm{Al}_{2} \mathrm{O}_{3}-\mathrm{H}_{2} \mathrm{O}$ ternary diagram 


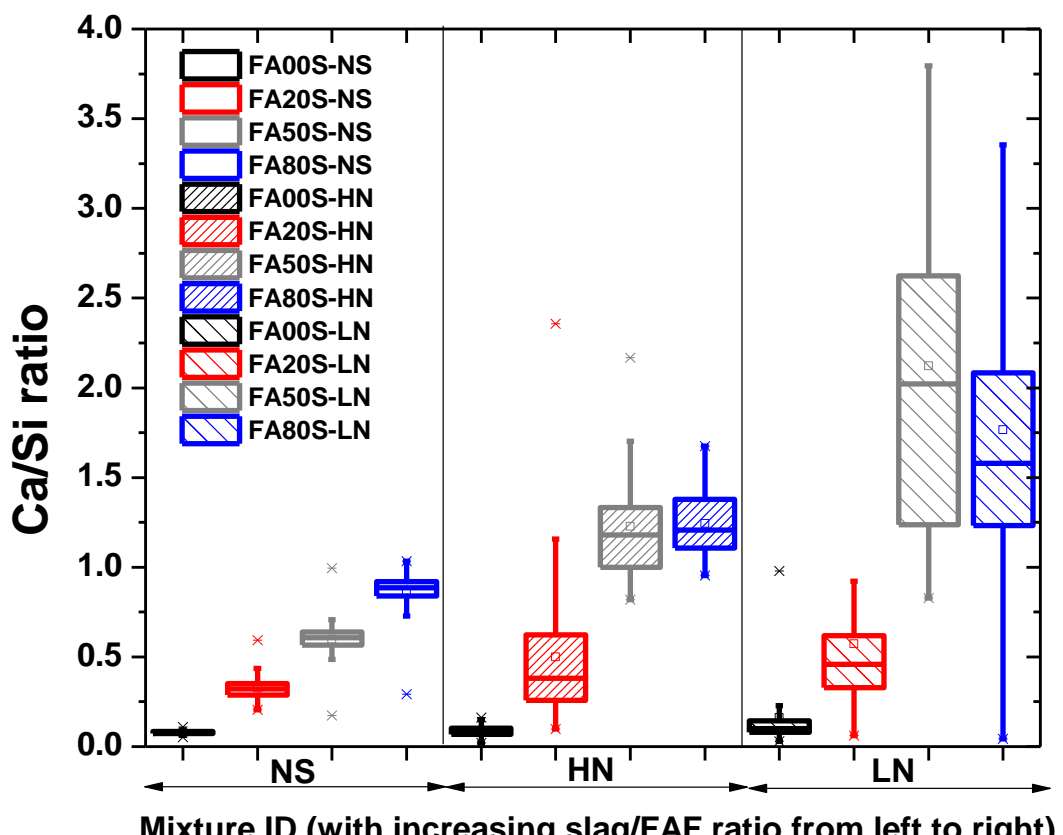

474

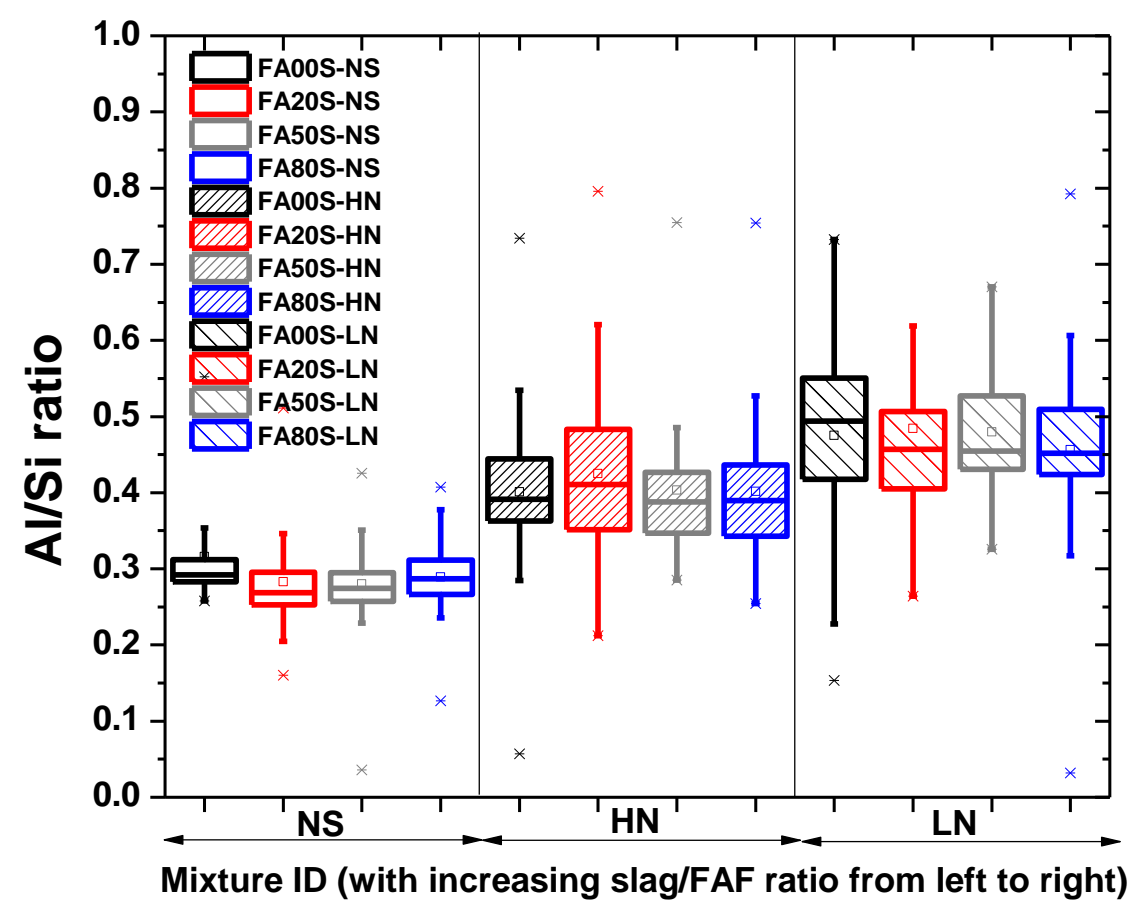




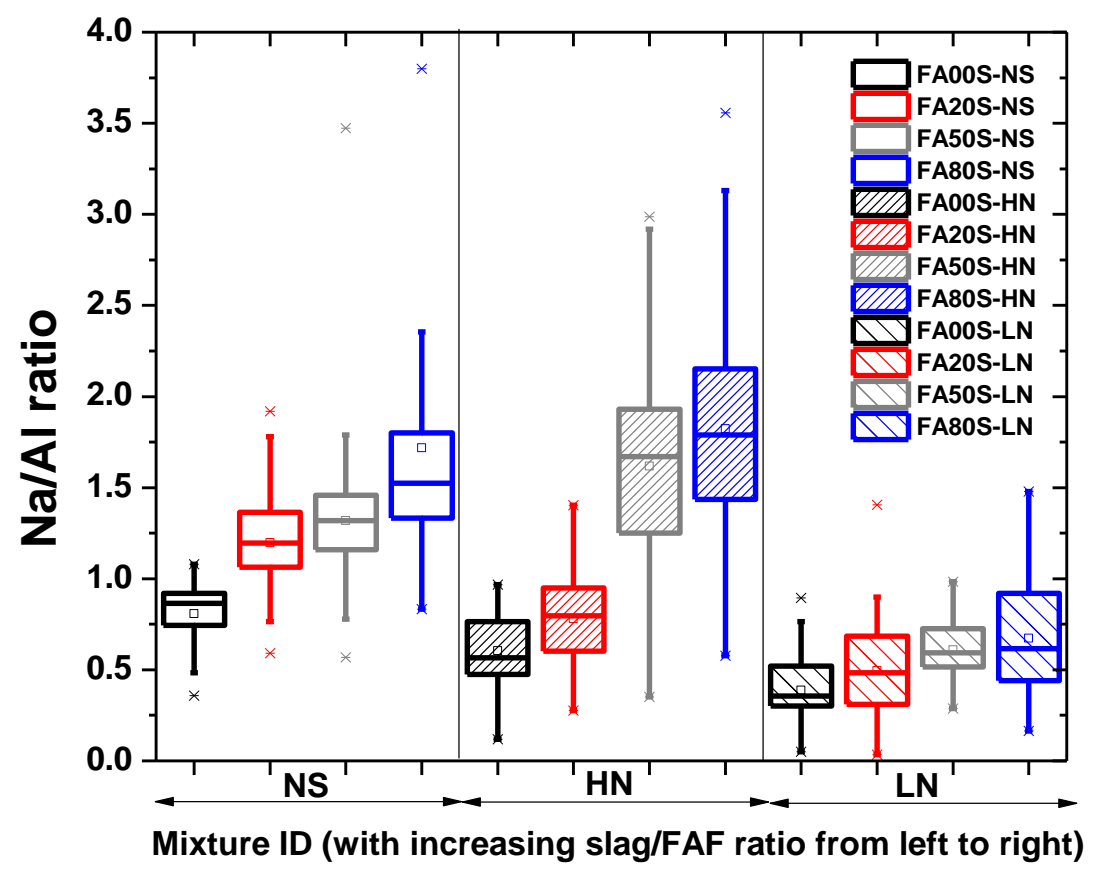

478

(c)

480 Figure 12 Box-and-whisker plot showing the statistical distribution of the chemical composition

481 of hydration products formed in NS-, HN- and LN-activated FA-F and slag binders with various 


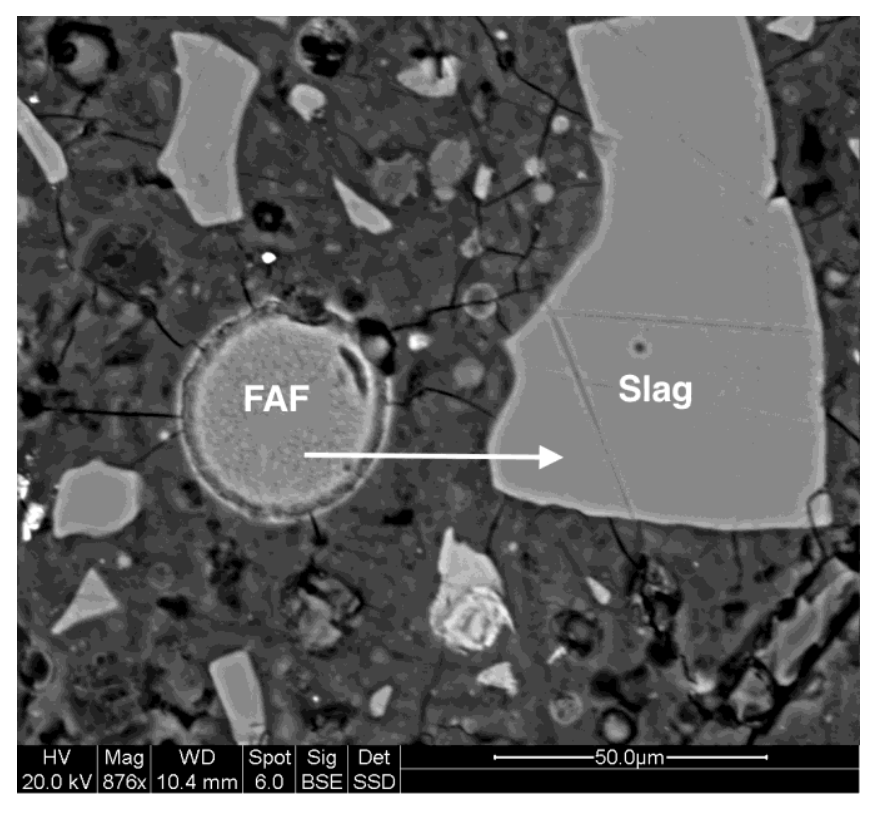

(a)
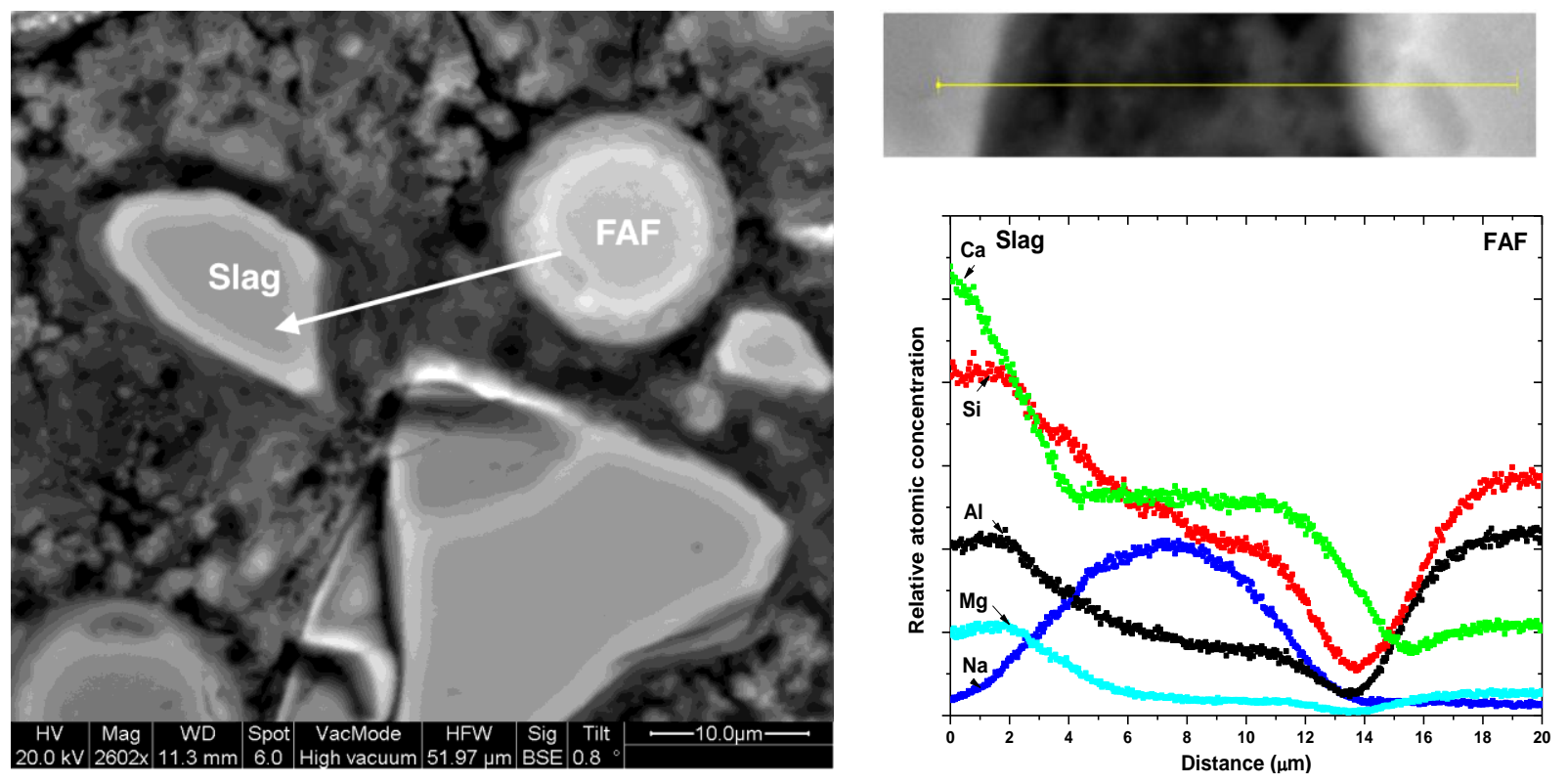

(b) 

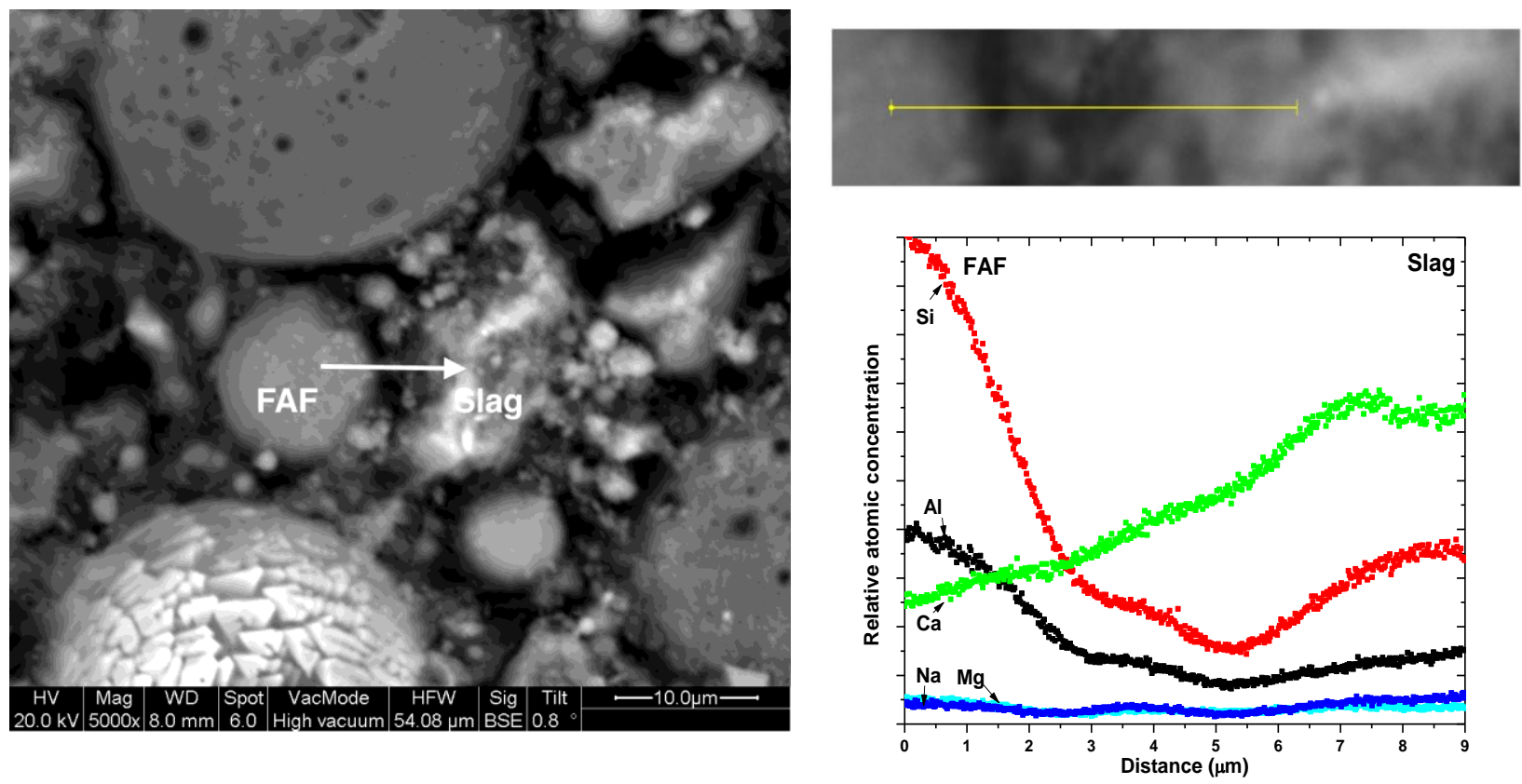

(c)

490 Figure 13 Line EDS results for the elemental distribution between two randomly selected

491 semi-hydrated FA-F and slag particles for FA50S activated by (a) NS; (b) HN; (c) LN

\section{4. Conclusions}

495 In this paper, the influence of activator type/dosage (i.e. [SiO2]aq, $\mathrm{pH}$ ) on the interaction

496 mechanisms between slag and FA-F is investigated. The following conclusions can be drawn

497 according to this study:

498

499 (1) The experimental results based on XRD and SEM/EDS support that C-A-S-H and N-A-S-H 
500 gels can co-exist in binary FA-F/slag-based geopolymer. Furthermore, the hydration products

501 consist of various types of C-A-S-H and N-A-S-H gels, and the nature/configuration of the gels,

502 as well as the crystalline phases, are dependent on the mixing proportions (e.g. starting FA-F/slag

503 ratio and type/dosage of activator).

504

505 (2) For low slag/FA-F ratio, C-A-S-H is not likely to be formed at early age when activated by

506 sodium silicate, but can be found in sodium hydroxide solutions, based on ternary diagram

507 analysis.

508

509 (3) The microstructure of the binary FA-F/slag-based geopolymer is affected by FA-F/slag ratio

510 and type/dosage of the activator. Increasing slag proportion and introduction of [SiO2]aq in

511 activator can both densify the microstructure, while the mechanisms are different.

513 (4) Sodium silicate-activated mixtures possess structures that are more amorphous than

$514 \mathrm{NaOH}$-activated mixtures, as a result of suppressed formation of crystalline phases. In addition,

515 low $\mathrm{pH} \mathrm{NaOH}$ solutions promote the formation of more amorphous C-A-S-H (compared to

516 C-S-H (I)) and sulfate-bearing phases, while high $\mathrm{pH} \mathrm{NaOH}$ solutions promote formation of

517 alumina-modified C-S-H (I) and hydrotalcite-type phases.

519 (5) For a given type of activator, the interaction mechanisms between FA-F and slag are 
520 primarily reflected in: (i) altering the structure (e.g. crystallology and lattice parameters) of

521 different phases, (ii) suppressing or triggering the formation of some crystalline phases, and (iii)

522 homogeneity of composition and microstructure.

524 (6) The activator has a considerable impact on the interaction between raw materials chemically,

525 structurally, and kinetically, through influencing in the formation of precipitates and

526 homogeneity of microstructure.

528 (7) The interaction between FA-F and slag occurs locally rather than uniformly and is likely to be

529 controlled by the dissolution/diffusion kinetics, and solubility/stability of the hydrated gels

530 (C-A-S-H, N-A-S-H, and possible (N-)C-A-S-H gels).

\section{Acknowledgements}

534 The authors gratefully acknowledge the financial support from the U.S. National Science

535 Foundation (NSF) under Award CMMI \#1265789. Any opinions, findings and conclusions or

536 recommendations expressed in this material are those of the authors and do not necessarily

537 reflect the views of the NSF. 


\section{$540 \quad$ References}

541 [1] Juenger M, Winnefeld F, Provis J, Ideker J. Advances in alternative cementitious binders.

542 Cement and Concrete Research. 2011;41(12):1232-43.

543 [2] Thomas RJ, Ye H, Radlińska A, Peethamparan S. Alkali-activated slag concrete: A closer

544 look at sustainable alternatives to portland cement. Concrete International. 2016;38(1):33-8.

545 [3] Luo X, Xu J, Bai E, Li W. Systematic study on the basic characteristics of alkali-activated

546 slag-fly ash cementitious material system. Construction and Building Materials. 2012;29:482-6.

547 [4] Yip CK, Lukey G, Van Deventer J. The coexistence of geopolymeric gel and calcium silicate

548 hydrate at the early stage of alkaline activation. Cement and Concrete Research.

$5492005 ; 35(9): 1688-97$.

550 [5] Fernández-Jiménez A, Palomo A. Composition and microstructure of alkali activated fly ash

551 binder: effect of the activator. Cement and Concrete Research. 2005;35(10):1984-92.

552 [6] Ye H, Cartwright C, Rajabipour F, Radlińska A. Effect of drying rate on shrinkage of

553 alkali-activated slag cements. 4th International Conference on the Durability of Concrete

554 Structure (ICDCS). Purdue University, Indiana, USA2014. p. 254-61.

555 [7] Ye H, Radlińska A. A review and comparative study of existing shrinkage prediction models

556 for portland and non-portland cementitious materials Advances in Materials Science and

557 Engineering. 2016;2016(2016):Article ID: 2418219.

558 [8] Ye H, Radlińska A. Quantitative analysis of phase assemblage and chemical shrinkage of 559 alkali-activated slag. Journal of Advanced Concrete Technology. 2016;14:245-60. 
560 [9] Lee N, Jang J, Lee H. Shrinkage characteristics of alkali-activated fly ash/slag paste and 561 mortar at early ages. Cement and Concrete Composites. 2014.

562 [10] Duxson P, Provis JL, Lukey GC, Mallicoat SW, Kriven WM, Van Deventer JS.

563 Understanding the relationship between geopolymer composition, microstructure and mechanical

564 properties. Colloids and Surfaces A: Physicochemical and Engineering Aspects. $5652005 ; 269(1): 47-58$.

566 [11] Pacheco-Torgal F, Castro-Gomes J, Jalali S. Alkali-activated binders: A review: Part 1.

567 Historical background, terminology, reaction mechanisms and hydration products. Construction 568 and Building Materials. 2008;22(7):1305-14.

569 [12] Li C, Sun H, Li L. A review: The comparison between alkali-activated slag ( $\mathrm{Si}+\mathrm{Ca})$ and 570 metakaolin (Si+ Al) cements. Cement and Concrete Research. 2010;40(9):1341-9.

571 [13] Richardson I. The nature of CSH in hardened cements. cement and concrete research. $572 \quad 1999 ; 29(8): 1131-47$.

573 [14] Richardson I, Brough A, Groves G, Dobson C. The characterization of hardened 574 alkali-activated blast-furnace slag pastes and the nature of the calcium silicate hydrate (CSH) 575 phase. Cement and Concrete Research. 1994;24(5):813-29.

576 [15] Taylor HF. Cement chemistry: Thomas Telford; 1997.

577 [16] Renaudin G, Russias J, Leroux F, Cau-dit-Coumes C, Frizon F. Structural characterization 578 of $\mathrm{C}-\mathrm{S}-\mathrm{H}$ and $\mathrm{C}-\mathrm{A}-\mathrm{S}-\mathrm{H}$ samples-Part II: Local environment investigated by spectroscopic 579 analyses. Journal of Solid State Chemistry. 2009;182(12):3320-9. 
580 [17] Provis JL, Van Deventer JSJ. Geopolymers: structures, processing, properties and industrial 581 applications: Elsevier; 2009.

582 [18] Davidovits J. Geopolymers. Journal of Thermal Analysis and Calorimetry. 583 1991;37(8):1633-56.

584 [19] Franus W, Wdowin M, Franus M. Synthesis and characterization of zeolites prepared from 585 industrial fly ash. Environmental monitoring and assessment. 2014:1-9.

586 [20] Ismail I, Bernal SA, Provis JL, San Nicolas R, Hamdan S, van Deventer JS. Modification of 587 phase evolution in alkali-activated blast furnace slag by the incorporation of fly ash. Cement and 588 Concrete Composites. 2014;45:125-35.

589 [21] Lloyd RR, Provis JL, van Deventer JS. Microscopy and microanalysis of inorganic polymer 590 cements. 2: The gel binder. Journal of Materials Science. 2009;44(2):620-31.

591 [22] Lee N, Lee H. Reactivity and reaction products of alkali-activated, fly ash/slag paste.

592 Construction and Building Materials. 2015;81:303-12.

593 [23] Puligilla S, Mondal P. Role of slag in microstructural development and hardening of fly 594 ash-slag geopolymer. Cement and Concrete Research. 2013;43:70-80.

595 [24] Kumar S, Kumar R, Mehrotra S. Influence of granulated blast furnace slag on the reaction, 596 structure and properties of fly ash based geopolymer. Journal of Materials Science.

$597 \quad 2010 ; 45(3): 607-15$.

598 [25] Ryu GS, Lee YB, Koh KT, Chung YS. The mechanical properties of fly ash-based 599 geopolymer concrete with alkaline activators. Construction and Building Materials. 
2013;47:409-18.

601 [26] Chithiraputhiran S, Neithalath N. Isothermal reaction kinetics and temperature dependence 602 of alkali activation of slag, fly ash and their blends. Construction and Building Materials. $603 \quad 2013 ; 45: 233-42$.

604 [27] Provis JL, Myers RJ, White CE, Rose V, van Deventer JS. X-ray microtomography shows 605 pore structure and tortuosity in alkali-activated binders. Cement and Concrete Research. $6062012 ; 42(6): 855-64$.

607 [28] Rietveld H. A profile refinement method for nuclear and magnetic structures. Journal of 608 applied Crystallography. 1969;2(2):65-71.

609 [29] Warren BE. X-ray Diffraction: Courier Corporation; 1969.

610 [30] De Silva P, Sagoe-Crenstil K. Medium-term phase stability of Na 2 O-Al 2 O 3-SiO 2-H 2

611 O geopolymer systems. Cement and Concrete Research. 2008;38(6):870-6.

612 [31] Wang S-D, Scrivener KL. Hydration products of alkali activated slag cement. Cement and 613 Concrete Research. 1995;25(3):561-71.

614 [32] Ben Haha M, Le Saout G, Winnefeld F, Lothenbach B. Influence of activator type on 615 hydration kinetics, hydrate assemblage and microstructural development of alkali activated 616 blast-furnace slags. Cement and Concrete Research. 2011;41(3):301-10.

617 [33] Ye H, Radlińska A. Shrinkage mechanisms of alkali-activated slag. Cement and Concrete 618 Research. 2016;(Under Review).

619 [34] Oh JE, Monteiro PJ, Jun SS, Choi S, Clark SM. The evolution of strength and crystalline 
620 phases for alkali-activated ground blast furnace slag and fly ash-based geopolymers. Cement and

621 Concrete Research. 2010;40(2):189-96.

622 [35] Garcia-Lodeiro I, Palomo A, Fernández-Jiménez A, Macphee D. Compatibility studies

623 between NASH and CASH gels. Study in the ternary diagram Na 2 O-CaO-Al 2 O 3-SiO 2-H 2

624 O. Cement and Concrete Research. 2011;41(9):923-31.

625 [36] Granizo ML, Alonso S, Blanco - Varela MT, Palomo A. Alkaline activation of metakaolin:

626 effect of calcium hydroxide in the products of reaction. Journal of the American Ceramic 627 Society. 2002;85(1):225-31.

628 [37] Lee N, Lee H. Setting and mechanical properties of alkali-activated fly ash/slag concrete 629 manufactured at room temperature. Construction and Building Materials. 2013;47:1201-9.

630 [38] Garcia-Lodeiro I, Fernández-Jiménez A, Palomo A. Variation in hybrid cements over time. 631 Alkaline activation of fly ash-portland cement blends. Cement and Concrete Research. $632 \quad 2013 ; 52: 112-22$.

633 [39] Garcia-Lodeiro I, Palomo A, Fernández-Jiménez A, Macphee D. Compatibility studies 634 between NASH and CASH gels. Study in the ternary diagram $\mathrm{Na}<\mathrm{sub}>2</ \mathrm{sub}>\mathrm{O}-\mathrm{CaO}-\mathrm{Al}<$ $635 \mathrm{sub}>2</ \mathrm{sub}>\mathrm{O}<\mathrm{sub}>3</ \mathrm{sub}>-\mathrm{SiO}<\mathrm{sub}>2</ \mathrm{sub}>-\mathrm{H}<\mathrm{sub}>2</$ sub $>\mathrm{O}$. Cement and Concrete 636 Research. 2011;41(9):923-31.

637 [40] Gebregziabiher BS, Thomas R, Peethamparan S. Very early-age reaction kinetics and 638 microstructural development in alkali-activated slag. Cement and Concrete Composites. $6392015 ; 55: 91-102$. 